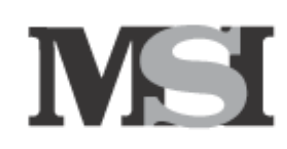

Marketing Science Institute Working Paper Series 2011

Report No. 11-101

\title{
Effective Marketing Science Applications: Insights from ISMS-MSI Practice Prize Finalist Papers and Projects
}

\author{
Gary L. Lilien, John Roberts, and Venkatesh Shankar
}

"Effective Marketing Science Applications: Insights from ISMS-MSI Practice Prize Finalist Papers and Projects" (C) 2011 Gary L. Lilien, John Roberts, and Venkatesh Shankar; Report Summary (C) 2011 Marketing Science Institute

MSI working papers are distributed for the benefit of MSI corporate and academic members and the general public. Reports are not to be reproduced or published, in any form or by any means, electronic or mechanical, without written permission. 


\section{Report Summary}

Established in 2003, the Informs Society for Marketing Science-MSI Practice Prize competition honors the outstanding implementation of marketing science concepts and methods. As of 2010, 22 projects have been finalists in the competition.

Each project represents a remarkable success story that illustrates the impact of marketing science, both in a specific situation and in its potential for broader applications. Each project also has overcome the hurdle of commercial success: its success and organizational impact have been documented in presentations at the prize competition (see http://techtv.mit.edu/collections/isms), and the details have been published in Marketing Science.

The 22 finalists represent a wide range of applications (e.g., marketing strategy, sales force, customer lifetime value, advertising, direct marketing), and also reflect industries as diverse as automotive, consumer packaged goods, catalog sales, airlines, insurance, and telecommunications, with implementations spanning four continents. They also report the use of a vast spectrum of marketing science models and analytic methods.

In this report, the authors analyze the 22 finalists using three sources of data-the published papers, responses of the finalist authors to a survey question battery, and in-depth interviews with the authors.

They offer four major takeaways from their analysis. First, there is great upside potential in applying marketing science models and methods to business problems. Second, there are usually three sets of actors - practitioners, academics, and consultants/intermediaries - involved in successful applications. Third, there are important gaps between the goals and reward structures of these three groups. Finally, and importantly, there are some readily implementable ways to bridge those gaps to the benefit of all.

Further, their analysis suggests that, although some factors clearly correlate with impactful research, there are multiple pathways through which a project can add value to its client organization. Sometimes, simpler, easier-to-use models offer robust results have greater influence than more rigorous, sophisticated models. As with any new mode of operating, organizational buy-in is critical; such buy-in can be achieved through high-level champions, inhouse presentations and dialogue, pilot assignments, the involvement of personnel from multiple departments, and the use of the same language as influential executives.

The authors offer six recommendations for marketing academia: (1) add "impact" to the promotion and tenure process, at least for promotion to full professor, (2) encourage leaves and sabbaticals for practice work, especially with intermediaries, (3) add internships to doctoral programs, (4) require at least one letter from a nonacademic reference in promotion and tenure dossiers, (5) consult in return for data and problem access, and (6) embrace some form of the medical or education school model that integrates practice into both research and education.

The authors offer five recommendations for consultants and intermediaries: (1) recognize the possibility of breakthrough work that could lead to new lines of business, achieved by working 
with academics, (2) leverage the publicity and credibility of copublishing with academics, (3) seek appropriate academic partners at both academic conferences and industry conferences, (4) offer internships to faculty and Ph.D. students, and (5) seek creative business relationships with business schools (e.g., research/consulting blends) such that they embrace the medical school model for mutual gain.

Finally, the authors offer five managerial recommendations: (1) engage academics in just-in-time education to learn marketing concepts and models in the context of the marketing problem or issue, (2) document and communicate both short- and long-term (and soft and hard) benefits of such interactions, (3) take marketing analytics courses with real content, (4) document model and MDSS failures, as well as successes, to enable future success that builds on those failures; and (5) experiment with marketing models. Some will fail. But as Prof. Robin Hogarth of the University of Chicago has noted, "When driving at night with your headlights on, you do not necessarily see too well. However, turning your headlights off will not improve the situation.”

Gary L. Lilien is Distinguished Research Professor of Management Science and Research Director, Institute for Study of Business Markets (ISBM), Smeal College of Business, Penn State University. John Roberts is Professor of Marketing, at the School of Australian National University and London Business School. Venkatesh Shankar is Professor of Marketing and Coleman Chair in Marketing, Mays Business School, Texas A\&M University.

\section{Acknowledgments}

We thank the Marketing Science Institute for financial support. We also are grateful to Michael Lowe for research assistance and Lori Nicolini for administrative support. Finally, we thank all the authors of the practice prize articles for their cooperation and insights. Please address all correspondence to Venkatesh Shankar (vshankar@mays.tamu.edu). 
In 2003, ISMS (Informs Society for Marketing Science) introduced a Practice Prize to be awarded to the most outstanding implementations of marketing science concepts and methods. The methodology used had to be sound and appropriate for the management problem and organization; the work had to have significant, verifiable, and preferably quantifiable impact on the client organization's performance. In other words, the award was designed to recognize both the rigor of the work and its relevance and organizational impact. Other awards (e.g., Little Award, Bass Award) recognize outstanding rigor in marketing science; the ISMS Practice Prize goes one step further by recognizing that developing an innovation that works in the laboratory is important, but achieving commercial adoption and influence through that innovation is key. Beginning with the 2009-2010 competition, the Marketing Science Institute (MSI) became a cosponsor of the award, making it the ISMS-MSI Practice Prize. ${ }^{1}$ This cooperation is entirely appropriate, in that ISMS and MSI exemplify rigor and relevance, respectively, in marketing science. Since its inception, the award has recognized 22 pieces of work as finalists and winners (see Table 1) in the competition. Each work represents, in its own way, a remarkable success story that illustrates the impact of marketing science, both in a specific situation and in its potential for broader applications. Each project also has overcome the hurdle of commercial success. Their success and organizational impact have been documented in presentations at the prize competition (see http://techtv.mit.edu/collections/isms), and the details have been published in Marketing Science (with one exception). (Tables follow References throughout.)

${ }^{1}$ The award will be renamed the Gary L. Lilien ISMS-MSI Practice Prize beginning in 2011-2012. 
What can we learn from this set of successful marketing science applications? Quite a lot, it turns out. Not only do these finalists represent a wide range of applications (e.g., marketing strategy, sales force, customer lifetime value, advertising, direct marketing), but they also reflect industries as diverse as automotive, consumer packaged goods, catalog sales, airlines, insurance, and telecommunications, with implementations spanning four continents. They also report the use of a vast spectrum of marketing science models and analytic methods.

In this article, we review these award-winning papers, examine their influence on relevant organizations, and consider the diffusion and impact of the marketing science models they propose. We also draw lessons from our synthesis of these 22 important applications. We blend three sources of data - the published papers, responses of the authors of the papers to a survey question battery, and in-depth interviews with the authors. By reviewing the finalists of the ISMS-MSI Practice Prize to date, we address four objectives: (1) identify the common factors that characterize finalist papers and projects, (2) cluster projects with specific shared characteristics, (3) formulate and explain a framework for the successful development and application of marketing science models, and (4) offer insight into the diffusion and impact of marketing science models, with implications for academics, practitioners, and intermediaries.

Our review reveals several important findings. Effective marketing science applications span a wide range of managerial problems, using an extensive variety of marketing science techniques. We find that though some factors clearly correlate with impactful research, there are multiple pathways through which a project can add value to its client organization. The projects show that sometimes simpler, easier-to-use models that offer robust results have greater influence than more rigorous, sophisticated models. As with any new mode of operating, organizational buy-in is critical; such buy-in can be achieved through high-level champions, in- 
house presentations and dialogue, pilot assignments, the involvement of personnel from multiple departments, and the use of the same language as influential executives. Finally, intermediaries often play a vital role in the transportability of models across organizations.

We thus proceed as follows: In the next section, we provide a synthesis of the award finalist projects - problems addressed, methods used, and authors' perceptions of the project characteristics. We then offer a framework for understanding the process of development and implementation of marketing science models in organizations and discuss the key elements of the framework. With this framework, we can synthesize the lessons that the studies' authors draw from their specific projects to apply them more broadly to the use and impact of marketing science models in industry. In a subsequent section, we give an overview of the diffusion of marketing science models in practice and focus on the gap between managers and academics with regard to marketing science models, along with some suggestions for narrowing this gap. We close by highlighting the lessons from our review and outlining implications for academics, managers, and intermediaries.

\section{Characteristics of the Finalist Projects}

Following Bell and Anderson (2002) and Bell, Anderson, and Kaiser (2002), we administered a survey and interviewed key project members from each team to investigate the genesis, implementation details, and impact of these projects, including reasons for their continued adoption or disadoption by the organization (for the cover letter, questionnaire, and interview protocol, see Web Appendix 1). In each case, one author conducted the interview 
(average 45-60 minutes, though one interview involved two one-hour sessions). ${ }^{2}$ The interviews were recorded and transcribed and provide the data for much of our qualitative analysis and discussion. We provide a list of the finalists papers, relevant organizations, corresponding marketing decisions, and associated marketing science models in Table 1.

Question 11 of the questionnaire (see Web Appendix 1) comprises subquestions (items) with close-ended answers that help characterize and classify the projects. The summary statistics of the responses to this question appear in Figure 1. The average practice prize organization was not analytically strong, used few if any marketing mix optimization models, and had no recognized reward structure for those who introduce marketing science models. Furthermore, the average project required a strong internal advocate to succeed. (Figures follow References throughout.)

An exploratory factor analysis on the items, using principal components analysis (PCA) with Varimax rotation, revealed a three-factor solution, according to both the scree plot and interpretability criteria. Table 2 contains the results of that analysis, with our interpretation of three factors: (1) strategically savvy, (2) an evidence-based culture, and (3) advanced, both analytically and in terms of information technology (IT). If we plot the winning entries' scores on the first and third factors for example (Figure 2), we find that some organizations are far more advanced than others in their analytical capabilities, whereas others are far more strategically savvy. Depending on the combination of their scores, we divide the firms into four quadrants. Those with high analytic skills and strategic savvy scores (e.g., Whirlpool, Procter \& Gamble [P\&G], JD Power DSSIP) represent "Strategic leveragers.” Firms with high analytic skills but low strategic savvy (e.g., bauMax) are "Operationally focused”. When organizations have high

\footnotetext{
${ }^{2}$ Two of the authors have been finalists for the award. Each was interviewed by a different author. All the authors of this article have served as judges in the competition.
} 
strategic savvy but low analytical skills (e.g., Jetstar, NAP), we refer to them as "outsourcers" (of marketing science models). Finally, firms that score low on both strategic savvy and analytical capabilities (e.g., Futuredontics, Inofec) are "greenfields enterprises" (with regard to marketing science applications).

To clarify the internal differences across applications, we cluster-analyzed them and provide, in Table 3, a three-cluster solution using k-means cluster analysis with the mean values of each cluster center. ${ }^{3}$ These data are both interpretable and interesting. Cluster 1 scores very low on the essential role of the $C E O$ (relative to Clusters 2 and 3), whereas Cluster 3 reveals a low score for use of mix optimization models and modeling at the product level, relative to Clusters 1 and 2. We therefore suggest there are many ways for a marketing science application to exert impact within an organization. It may not absolutely need the active engagement of the CEO (Cluster 1), but if it lacks this engagement, there must be good penetration of modeling elsewhere, because any project needs a champion. Consulting firms such as ZS Associates, JD Power, Clickthrough, Bayer, and bauMax constitute this cluster. They do not rely much on their CEOs but might lean on practice leaders to ensure the successful design and execution of a project. Nor is it necessary for an organization to have deeply embedded marketing modeling skills, which can be outsourced, as in Cluster 3. But for this strategy to succeed, the CEO must be actively engaged. Small firms offer good examples of firms in this cluster, such as Inofec and Futuredontics. Finally, in Cluster 2 both drivers are at work; this cluster also represents the majority of finalist firms. These firms tend to be large and well established, with strong strategic

\footnotetext{
${ }^{3}$ We chose a three-cluster solution on the basis of the number of members in each cluster and interpretability.
} 
thinking and analytical capabilities, including PepsiCo, Allstate, P\&G, Whirlpool, Prudential, Telstra, Jetstar, CVS, IBM, and Finnair. This cluster also includes a few smaller organizations, such as NAP, tele.ring, and Rhenania.

Projects also can be classified by the level and types of marketing decisions and type of methodologies adopted to make those decisions, as we show in Table 4. The marketing decisions that can be addressed most profitably with marketing science approaches range from strategic choices about responses to new entries to tactical decisions on price promotions. Analytical methods also span a wide array of techniques, including multidimensional scaling, regression analysis, and math programming. Regression analysis and choice models are the most common methods being used across a variety of applications and firms; optimization and math programming are also popular methods for multiple applications.

\section{A Framework of the Development and Application of Marketing Science Models}

Understanding the nature of the quantitative data provides a platform for us to examine how the 22 applications achieved their impact. In addition to this quantitative analysis, we have performed a detailed analysis of the open-ended sections of the interviews, which revealed surprising variation in the answers and several lessons.

We develop a new version of the organizational diffusion of innovations framework (Figure 3) to clarify and structure our findings. The framework offers a process structure that connects the elements involved in the identification, development, and application of marketing 
science models. Each project starts with the identification of a marketing decision problem, followed by commissioning the project and adopting the marketing science approach. The project then exerts an impact on the organization, leading to a decision to continue the implementation or transport the application to other areas. Factors such as triggers, drivers, barriers, and enablers influence the different stages in this process.

Using this framework, we identify characteristics or factors common to some or all ISMS-MSI Practice Prize finalist papers. We examine the presence of a corporate champion, the process of obtaining corporate buy-in, data availability, and the simplicity of the model adopted. We also examine differences across firms, including the triggers, drivers, barriers, and enablers for the project and determinants of project continuity and transfer. Finally, we discuss the organizational impact of the project and learning from the project in depth.

\section{Project triggers}

Projects start when connections develop in different ways between practitioners and academics. Some projects initiate because a new set of executives receives the mandate to effect a major change in the organization. In the Allstate project for example, the newly hired chief marketing officer $(\mathrm{CMO})$ challenged the organization to estimate and demonstrate the value of its brand. Tasked with this challenge, the lead executive reached out to an academic, because he did not believe a practicing consultant could handle such a problem. Alternatively, managers might receive a spark from reading an academic article and then contacting the authors (e.g., JD Power ODAV, Bayer, PepsiCo). However, some projects reflect ongoing relationships between the client organizations and academics, such as those involving CVS, IBM-CLV, JD Power 
DSSIP, Finnair/IBM, Clickthrough, and Campbell's. A personal connection between an academic and an executive of a firm thus can trigger a project, as for Inofec, PepsiCo, NAP, and Bayer. These connections or acquaintances of academics and practitioners can also create serendipity, as in the case of Inofec.

The connections might be mediated, such that we find some projects emerge through intermediary contacts (bauMax) or an academic's response to a request for proposal (e.g., Whirlpool, Jetstar, Telstra). Similarly, academics with a new technique or method might go in search of a problem (ZS, tele.ring); the NAP project was even an extension of an MBA field study led by the academic involved in the project.

Finally, many projects start when a default approach becomes unacceptable to the organization. Firms differ in their predictions about what they would have done without the benefit of a marketing science approach, such that Allstate, JD Power DSSIP, IBM-CLV, and Finnair/IBM would have carried on with their business as before. Companies like Bayer, Telstra, and PepsiCo indicate that they would have hired a consultant to do the project, but Rhenania had no alternative but to develop an innovative OR/MS approach to save the company. Whirlpool even would have discontinued marketing its product had it not commissioned the project.

\section{Project drivers}

When a practitioner-academic link has been established, the project is ready to start, though it needs some momentum to surmount obstacles. That is, the effective adoption of a project depends on the ability of its drivers to overcome any obstacles. In particular, no marketing science project could succeed without appropriate resources. Little (1979) lists several such resources, including models, statistics, data, and optimization. Sometimes consultants 
themselves are important drivers (e.g., ZS, JD Power DSSIP, JD Power ODAV, Finnair/IBM, Clickthrough, Campbell's). However, projects by Allstate, Bayer, Whirlpool, NAP, P\&G Asia Pacific, IBM-CLV, Prudential, Inofec, Rhenania, and tele.ring used no outside consultants, and for the projects for CVS, Telstra, Jetstar, and bauMax, academics partnered with the consultants.

\section{Project barriers}

Barriers to the birth and progress of projects come in many forms. In firms like Allstate, JD Power ODAV, and Bayer, the lack of executives' time and need for onsite involvement were significant barriers. Many projects required changes to the culture or mental models among relevant executives (e.g., Allstate, JD Power ODAV, Whirlpool, NAPs, IBM-CLV, P\&G AsiaPacific, Clickthrough, tele.ring, Inofec). Academics and practitioners differ considerably in terms of the time horizon of their work. Many academics treat firm projects as they would a research project, focusing on rigor and complete due diligence, with little regard for the length of the time horizon. In contrast, practitioners expect concentrated focus and quick results. The time horizon thus became a significant issue in the Bayer, PepsiCo, and Telstra projects. Furthermore, different perspectives and social norms characterize academic and practitioner communities. In academic circles, working on practical, applied research projects has negative connotations, whereas in the practitioner community, executives working on projects that encompass leadingedge methodology likely gain a reputation as being impractical or unaligned with the social environment.

Some projects cannot gain traction without the involvement of multiple stakeholders or buy-in from key executives in other functional areas (e.g., finance or IT). This problem is particularly acute early in the project, when the marketing department must convince other 
departments of the value of the project. At the Allstate insurance company, a strategic project required the approval and involvement of the finance and accounting departments. Because marketing was in disfavor before the new CMO took over, any major marketing investment required strong buy-in from the financial controller. Similarly, in the JD Power DSSIP project, automobile dealers had to be involved for the project to succeed. At ZS, field sales representatives constituted a major stakeholder community who needed to support the model; at Campbell's, the retailers were the critical stakeholders for any successful implementation.

Data collection, integration, and management can also pose sizable burdens. At Inofec and bauMax, data integration and management became formidable challenges, whereas the main concern for the Campbell's project was the time and cost of ensuring data availability. In turn, connecting the data to actions can be difficult. An author of the tele.ring project noted, "One barrier is establishing the link from insight to action," and an Inofec author concurred, "Lots of data and lots of action, but no link between the two."

The lack of links in some cases resulted from significant communication problems (e.g., JD Power ODAV, ZS, Finnair/IBM, IBM-CLV), both within the organization and across firms. At JD Power DSSIP, constant tension separated the sales and marketing departments; similar conflicts were prevalent at Telstra, CVS, Clickthrough, and IBM-CLV. Using a marketing science tool to make decisions might overcome an inherent tension, but in the words of a bauMax author, "There is a tension between disenfranchising managers and using a tool for decision making." 
Project enablers

Buy-in requires a strategy, such as a pilot or proof-of-concept exercise, as exemplified by Rhenania and Inofec. Each project comprised various enablers, because to move the organization along the path to implementation requires that "We took them on a journey" (Inofec author), which is why Finnair/IBM ensured it "did lots of training sessions and made results accessible." Top management involvement or drive (e.g., Jetstar, Prudential, Inofec, Rhenania, Telstra, Allstate, Bayer) and early demonstration of value or a high return on investment (ROI; Inofec, JD Power DSSIP, IBM-CLV, Pepsi, Rhenania, Bayer) were clearly critical. Other key tactics included a practical solution and applied wisdom (e.g., ZS), implementation aids such as visualization tools (tele.ring), web-based dashboards (JD Power DSSIP), training sessions (Telstra), and .Net and Excel (PepsiCo) . At Inofec, technical and lay descriptions of the results enhanced communication within the organization. The Finnair/IBM project got a great lift when the executives charged with internal communications focused on the main concepts using examples and prototypes, rather than technical details.

Several quotes from the bauMax study summarize the benefits of iterations and demonstrations in crafting, adapting, and communicating solutions: "Some good solutions are reached in the meantime," "We went into the field and showed success," and "We had formal test and validation scores against benchmarks." The Campbell's informants acknowledged that "Information gave us points of proof to gain confidence." Good success metrics also can be good enablers (e.g., profits at tele.ring, benchmarks at bauMax). Because demonstrated success builds momentum, according to JD Power DSSIP: "The executive who championed the effort mentioned that with just this one test they [Chrysler] made more than they paid for the project." 
The need for a champion also was echoed by many studies, such that the support of CEO and operations executives enabled changes at Rhenania, and there was clear recognition that "We had a champion" (Campbell's) or "The CEO was quite convinced" (tele.ring).

Cultural immersion provided a strong facilitator at Finnair/IBM, and trust is an important enabler as well. At Inofec, trust was critical for translating the problem into a solution. According to the author of the Campbell's project, "The firm does not need to look under the bonnet. They just need to trust the people that do."

\section{Impact of the project on the organization}

All the projects had remarkable short-term impacts on their respective organizations, but some projects went even further, such that they continue to run in the companies (e.g., Allstate, Rhenania, JD Power DSSIP, Bayer, ZS, NAP, Jetstar). However, a few firms terminated their projects, for various reasons; JD Power ODAV ended its project primarily because of the slump in the auto industry.

Although all the projects had substantial impacts, each differed and provided unique benefits. The Jetstar project enabled the firm to earn profits, even amid industry-wide losses, and the Campbell's project helped it grow sales faster than its category growth rate in a slowing economy. Because P\&G Asia Pacific already enjoyed value growth, its project offered a new approach to managing that growth. For the Prudential project, the outcome was greater awareness of behavioral risk but also a sizable lift in variable annuity sales. At Inofec, the project helped transform the company from an ad hoc decision-making organization to a highly analytical one; at NAP, it resulted in an analytical mindset and pricing structure, even in this nonprofit organization that had been using relatively simplistic methods. For JD Power ODAV, the new distribution system created through the project enabled it to reroute more than 2 million 
vehicles. Finally, the Telstra project provided a pre-launch framework for developing a strategy to combat a new entrant about which no reliable public information was available.

Many models had immediate financial impact, such as the promotion models for JD Power, bauMax, Clickthrough, and CVS. At JD Power DSSIP, the project contributed to new learning about a menu approach to automobile promotional strategies. The promotion decision support system at bauMax significantly improved both sales and profits, and the Clickthrough project achieved a transformative online promotions strategy. The unique CVS promotional tool application instead identified the categories that should not be promoted.

With regard to the medium- or long-term impact, we note the distinctive sales territory design model developed for ZS; it involved cumulative learning from model insights and expert judgments from hundreds of clients. In turn, organizations that used the modeling approach achieved continuous innovations. The Allstate project was pivotal in establishing a strong marketing-finance collaborative approach to address strategic issues within the organization, and then it changed the perception of marketing among top management (including finance), from an expense to an investment. As a result of its implementation of a forecasting model, PepsiCo now enjoys the long-term benefit of combining rigorous analytical modeling with practical relevance for rapid, fact-based decision making. The application of multilevel direct marketing modeling at Rhenania was so successful that it bought out several of its competitors. Tele.ring's transformation was perhaps even more dramatic: The CEO "flew to the U.S. with the map in his pocket. The map enabled him to sell the strategy to the company's investors. The resultant pricing regime then enabled him to command a considerably higher valuation for the company."

Yet other benefits were unexpected. The tele.ring project introduced a visually oriented, analytic culture to the firm for its tariff development or pricing decisions. At IBM-CLV, a 
stronger customer-oriented culture took hold in a firm that had been deeply rooted in technology.

The customer lifetime value-based optimization model at Finnair/IBM created a new mindset for managing loyalty programs for the long term, rather than simply managing promotional campaigns with the loyalty database. Finally, implementing a sales takeoff prediction model enabled Whirlpool to avoid dropping a proposed successful product.

\section{Organizational learning from the project}

The firms learned a lot from their projects, but their opinions differed widely with regard to what they would have done differently, were they to do the projects again. That is, some firms said they would have not altered anything (e.g., Rhenania, Whirlpool, IBM-CLV, P\&G Asia Pacific, Prudential). But firms such as Bayer, Allstate, and NAP would have involved intermediaries earlier or more deeply in the project, and academics wanted to spend more time with the organization. In the words of the Bayer author, "If I had it to do over again, I would have a partner on site $100 \%$ of the time helping implement at the organization." However, not all firms perceived the value of such intermediaries; one firm even asserted that more consultation would have gotten in the way and made the project more difficult to implement.

In line with the findings regarding project drivers, many firms (e.g., Inofec, Bayer) would have budgeted more time for data gathering, handholding, and onsite visits; tele.ring would have asked for more resources; and CVS would have collected more data. Many firms also would have liked to spend more time on communication and education within the organization, to effect changes to their mental models. A quote from Clickthrough makes this point in a colorful way: "I would have bought more beer for my web developers to build better bridges." JD Power ODAV 
and CVS would have followed simpler methods, though Inofec would have thought about the academic contribution earlier, as it emerged from addressing an important management problem.

Yet company learning extended beyond the identification of weak areas or mistakes. Some firms considered directional insights just as important as quantitative guidance. For example, Rhenania asserted that "management needed to optimize long-term profitability, not customer satisfaction," noting they went from a culture of "less is more" (focusing only on customers profitable in the short run) to "more is more" (including many customers unprofitable in the short run but profitable in the long run). Participating in the practice prize competition significantly enhanced some firm's marketing science capabilities, such that "We have learned so much from entering the Prize [competition]" (Rhenania).

These points are not to suggest that firms failed to realize the importance of making the application useful. To quote a Finnair/IBM respondent, "It is important to move away from the mathematics barrier to innovation. The review process is based on formalism. It should not be a show of technical prowess; it should be much more a show of what makes [an application] seem useful." The tele.ring respondent listed practical lessons: "The market was quite heterogeneous. We showed the benefits of treating it that way"; "The rate limiting step in most applications is not the method"; "We should work harder on the insight to action links"; and "For applications to be successful the links from analysis to strategy and from strategy to execution have to be present." Many of the respondents similarly could summarize their lessons briefly, such as when the Allstate marketing executives noted that "You have to start with a metric that the finance folks are comfortable with.” JD Power DSSIP explained that it learned that the need to connect with clients on their wavelengths is critical, such as by using Excel. Thus, client access to the most sophisticated model was not necessarily the best strategy if the client could not understand 
what the model did. Therefore, "the introduction of a .Net and Excel interface was a huge milestone because everyone on the client side knows how to use Excel. At the same time there was no need to compromise the sophistication and accuracy of the complex model that sat behind the interface." Similarly, at JD Power ODAV; "We were academics; we were not talking their talk. I remember one client who told me, 'I hear all that music but I don't hear the song'."

We again find some unexpected outcomes in terms of forms of learning. The insights extended beyond the anticipated realms, such as when a ZS executive explained, "Most academic work is not valuable to companies... In some cases you optimize, most often you satisfice. We found that if you come out of a computer with an alignment for a sales force of 100 people, 85 of them are going to want to kill you." An author of the PepsiCo project also came to the recognition that "The tenure process should give some weight to research-based consulting. We need to change the academic measurement and reward system."

We provide a rich collection of additional comments and quotes from the interviews in Web Appendix 2; Web Appendix 3 provides the abstracts of all the cited papers.

\section{Determinants of project continuation and transfer}

When a project has been implemented successfully, substantial challenges remain to sustaining its momentum. At bauMax for example, the key executives left, such that project adoption slowed and eventually stopped. At PepsiCo, the driving executives were recruited by other organizations. Although their successors wanted the academic authors to continue the project, they also expected them to participate in running the business, so the project did not spread as much as envisioned. Beyond retaining the knowledge of key actors, a project requires current and relevant insights, such that managers must address the transition from the 
development team. In the Campbell's project, the model needed continuous updating for example. Finally, solution transportability is critical to spread the modeling approach to other parts of the organization or other organizations. At PepsiCo, the forecasting model for soft drinks extended easily to business units that relied on direct-sales-delivery distribution as their main channel (e.g., salty snacks), because their data collection and decision-making processes were similar. However, for business units that relied on warehouse distribution (e.g., cereals), modifications were necessary to use the forecasting process.

\section{Implications for Diffusion and Impact of Marketing Science Models}

Lilien (2011) notes both upside potential and missed opportunities associated with the application and implementation of marketing science models; the 22 applications we analyze extend and deepen that discussion. Although models can produce significant benefits, many managers remain reluctant to use them; retail industry analysts report that retailers have been slow to adopt pricing decision models even when they are known to improve retail performance (Reda 2002). Sullivan (2005) reports that only $5 \%-6 \%$ of retailers use price-optimization models, and most prefer to rely on gut feelings for pricing decisions. Thus, "actual retail prices observed over time may differ greatly from model-recommended courses of action" (Nijs, Srinivasan, and Pauwels 2007, p. 473). Drawing from experience, Winer (2000, p. 143) reports:

My contacts in consumer products firms, banks, advertising agencies and other large firms say ... that models are not used much internally. Personal experience with member firms of the Marketing Science Institute indicates the same.... I have not seen the penetration of marketing modeling to which the authors refer.

Thus Roberts (2000, p. 130) is left to ask, 
What is it about conjoint analysis, customer satisfaction models and discriminant-based segmentation approaches that has lead to their managerial adoption while in relative terms diffusion models, game theoretic competitive analysis and multi-equation econometric models have languished in the hands of the manager?

Reflecting on what has changed since his seminal decision calculus paper (Little 1970),

Little (2004, p. 1858) notes that though technology, data, and methodology features have changed dramatically, two things remain the same: "organizational inertia and academic promotion criteria." He also quotes correspondence with Marshall Fisher:

Models can be deployed in one of two ways - either fully automated untouched by human hands or as a decision support system under the direction of a manager.... In the second mode, I have found that simple beats complex optimization every time because it enables a better coupling with the heavily involved manager ... most of my failures have come from tying to deploy sophisticated, black box optimization models in DSS environments because the managers with responsibility were unwilling to implement recommendations they did not understand (Little 2004, pp. 1857-58).

Fisher thus implies that successful implementations of sophisticated decision models demand automation; failures appear organizational rather than technical. Lodish (2001, p. S54) similarly describes his lessons from decades of building and applying successful models:

The criterion for a good, productive model is not whether it is theoretically or empirically perfect. It is whether the manager's decision, based on the model, improves productivity enough to justify the costs and resources devoted to developing and using the model.... This orientation has made it difficult to get some model descriptions into the best academic journals. However, I consider practical applications to be one of the most important attributes of my academic work.

Why should marketing academics be forced to make such trade-offs? Little (1979) argues that good marketing decision models are not enough but must be embedded in marketing decision support systems (MDSS) that also feature data, analytic tools, and computing power. Work on MDSS has followed but never become a mainstream topic in marketing literature. Wierenga and Van Bruggen $(1997,2000)$ argue that decision aids for marketing managers must match the thinking and reasoning processes of the decision makers who use them, but across 
different marketing problem-solving modes, they find no such thing as a single best MDSS. Zinkhan, Joachimsthaler, and Kinnear (1987) concur, because risk aversion, involvement, cognitive differentiation, and age all can predict MDSS use and satisfaction.

We might apply Rogers's (2003) diffusion of innovation factors (i.e., perceived advantage or benefit, purchase risk, ease of use, product complexity, immediacy of benefits, observability, trialability, price, extent of behavioral changes required, and ROI) to explain the gap between the potential and realized implementation of marketing models. The trialability issue is one Urban and Karash (1971) noted decades ago, discussing an evolutionary approach to model building. Their observations remain just as relevant today.

Most of these issues appear implicitly or explicitly in Wierenga, Van Bruggen, and Staelin's (1999) framework for determining the success of applying MDSS to marketing decision models. In particular, these authors recognize (1) demand-side issues, involving the characteristics of the decision problem, the specific decision maker, and the organizational environment in which the decision takes place; matched with (2) supply-side issues, or the characteristics of the system, including the data, knowledge base, and analytics or other underlying technology; (3) design characteristics of the MDSS itself; (4) the implementation process, including the characteristics and attitudes of the adopting organization and the process used by the system developers; and (5) success measures, such as attitudes toward the system, stakeholder success measures, and organizational success measures, both financial and otherwise. This extensive set of factors, along with the many drivers in Rogers's (2003) adoption criteria, suggests there are many potholes on the road to the successful implementation and use of marketing decision models. 
In addition to academics and client-practitioners, our interviews identified a third set of actors who should have been involved, and often were, in the projects, namely, intermediaries. Delaine Hampton, the Director of Consumer and Market Knowledge at Procter \& Gamble, indicated during a practitioner-academic interface session at the 2004 Marketing Science conference that she defines model success as changes to mental models within the organization. Success thus might be invisible, embedded in the operational system (automated marketing decision modeling) and integrated into a well-defined operational process (e.g., pricing or new product development processes, customer complaint resolution system). If it is visible and actively involves the decision maker though, users and the organization overall must change their ways of thinking if the project is to succeed.

Central to Hampton's description are intermediaries, such as marketing research firms and consultancies, that represent transfer agents in our models. Zoltners and Sinha (2005) won the ISMS Practice Prize, and ZS Associates, their consultancy (and an intermediary), employs more than 1000 employees in 17 offices worldwide to implement sales force models. They report shortcomings in their early years led to better models, but also and perhaps even more important better systems that aligned more closely with how sales managers actually made decisions and considered the cross-functional impact of those decisions. They developed modeling and system enhancements that enabled users to visualize an aligned solution. This description makes clear the analogy with Delaine Hampton's story: Better models and systems blend with use experience to develop better processes. Ultimately, as Zoltners and Sinha (2005, p. 320) acknowledge:

Territory alignment wisdom emerges, manifesting itself in knowledge, experience and perspective. The wisdom becomes part of subsequent alignments and frequently triggers further model, system and process innovation. Over time ... the role of processes and wisdom becomes larger than the role of the models and the systems. 
Thus Roberts, Kayande, and Stremersch (2009) use the term "marketing science value chain" to operationalize Hampton's view that marketing science intermediaries play key boundaryspanning roles for diffusing new technology and methodology throughout marketing. They cite two articles, by Guadagni and Little (1983) and Green and Srinivasan (1990), as exemplifying the combination of high academic and high managerial impact.

Guadagni and Little (2008, p. 26) comment on their 1983 paper in an anniversary retrospective, in which they provided a possible reason for its high impact in practice: "a small, entrepreneurial consulting firm developed and sold applications based on the model." The firm, Management Decision Systems, is the same one that commercialized Assessor (Silk and Urban 1978), an Edelman Prize finalist in 1989. Bucklin and Gupta (1999) also report on the widespread commercial use of models based on UPC scanner data (which drove the use of Guadagni and Little's logit model) and call intermediaries the primary transfer agents. Finally, the widespread impact of the various types of conjoint analysis demanded by Green and Srinivasan (1990) would not have emerged without many, highly skilled intermediaries who delivered key benefits.

So who are these intermediaries, and what is their role in the diffusion of marketing science models? Different segments include infrastructure vendors (e.g., SPSS), boutique vendors of model solutions (e.g., MDS), large generalist firms (e.g., BCG, McKinsey), implementation-oriented firms (e.g., Accenture), accounting firms (e.g., Deloitte), market research suppliers (e.g., Gallup), and so on. Each has a specific business model and incentives; all can span the marketing academic-practitioner gap to facilitate marketing decision models. 
Thus we identify three sets of actors involved in developing and implementing marketing decision models: academics, intermediaries, and practitioners (the ultimate model users). We provide suggests for all three sets, based on our analysis of the practice prize finalists.

\section{Conclusions and Recommendations}

Effective marketing science applications span a wide range of managerial problems and use an extensive variety of marketing science techniques. There is no one successful approach though, and even if some factors clearly are correlated with impactful research, there are many pathways through which a project can add value to its client organization. Academic involvement in a practice prize project starts mainly because (1) it can lend credibility and confidence to practical decisions (e.g., CVS, Allstate) and (2) marketing problems cannot be solved by existing methods proposed by in-house or practitioner consultants (e.g., Telstra, IBMCLV, Clickthrough). Simple, easy-to-use models that offer robust and improved results tend to exert a stronger impact than academically sophisticated but more accurate models (e.g., CVS, $P \& G)$. The initial implementation success depends on organizational buy-in, which can be achieved through high-level champions, in-house presentations and dialogue, pilot assignments, involvement of personnel from various departments, and creating a common language (e.g., Prudential, Clickthrough, Allstate). Continuity in both the practitioners involved and the organizational political dynamics are critical to the long-term success of the project (e.g., Futuredontics, Whirlpool, Pepsi). Evangelical dedication also is required to move the success of a marketing science model to other projects. Intermediaries play a major role in this transportability, so the diffusion of marketing science models is better served if they are involved 
(e.g., Jetstar, Telstra, CVS). Finally, academics' continuous involvement with practitioners is key to better model building and successful implementation of marketing science models (e.g., NAP, Allstate, IBM-CLV).

\section{Implications for academics}

Both Little (2004) and Lodish (2001) note that the academic reward system remains a barrier to the application of marketing decision models. One action seems clear: Make "impact on practice" an explicit element in the tenure and promotion process, together with publication in top journals, teaching, and service. Such an incentive would encourage academics to work (at least sometimes) with the intermediaries who implement the latest marketing models. The ISMS-MSI Practice Prize Competition and publication in Marketing Science represent a step in that direction. At Penn State University for example, Interfaces is considered a B+ academic journal for regular issues but an A-level publication for Edelman Prize papers, such that the school explicitly recognizes the value of practical impact and applications.

Some colleagues have argued that academics should wait to do applied work until after they get tenure - at which point they can work more closely with industry or intermediaries and offer consulting. Early on, they should concentrate on publishing in A-level journals and avoiding distractions. But the routes people choose during and immediately after their doctoral programs often constitute difficult-to-break habits.

Moreover, a key limitation for many marketing academics is data. One of our colleagues essentially consults for data. The contracts he signs with organizations that provide noteworthy and useful data state that he will offer consulting, based on his analytic and modeling expertise, that provides much deeper insights than they can get themselves; all he asks in return is to use 
the data in his academic publications. This happy situation allows the academic access to relevant, high-quality data and real business problems, as well as a means to apply the methods and models that he develops, which often lead to top-quality publications. The firm enjoys costeffective consulting. As he says, the "pay" is what most of us really value-top-quality, highimpact publications.

Perhaps we should embrace a version of the medical school model, in which both faculty and students (i.e., MBA and Ph.D. students in marketing) engage in ongoing work that involves real problems in real organizations. Schools of education often do something similar by opening their own preschools. We should develop our methods and skills by serving "patients," even as we continue writing articles. At the Colorado School of Mines, Gene Woolsey requires students who hope to graduate from the program to undertake a pro bono publico project for a company or agency. Any student, before or after graduation, who has saved his or her focal company, over the course of one year, at least $\$ 1$ million receives a diamond stickpin. The verified savings from this plan have exceeded $\$ 820$ million (see http://speakers.informs.org/bios/Woolsey.htm).

To summarize, we offer six recommendations for academics (for further discussion, see Roberts 2010): (1) add "impact" to our promotion and tenure process, at least for promotion to full professor; (2) encourage leaves and sabbaticals for practice work, especially with intermediaries; (3) add internships to doctoral programs; (4) require at least one letter from a nonacademic reference in promotion and tenure dossiers; (5) consult in return for data and problem access (rather than just for money); and (6) embrace some form of the medical or education school model that integrates practice into both research and education. 
Implications for intermediaries

We certainly cannot induce major changes in the fundamental intermediary reward system, because intermediaries are in business to make money. But if academics partner with them, copresent with them at conferences, and coauthor papers with them, intermediaries can generate the reputational capital that makes clients listen more closely to them when they describe the benefits of leading-edge models and methods. We recognize at least two barriers though: Intermediaries find little incentive to write for academic journals, and they often fear the loss of intellectual property through such disclosures.

Academics can answer the former concern through coauthorships facilitated by internships and industry sabbaticals. Intermediaries that share their methodology rarely lose business to their rivals; rather, they tend to increase the size of the market overall. When Silk and Urban (1978) published their work on Assessor, they helped legitimize the market for pretest market models; the intermediary Management Decision Systems reaped the benefits, especially after Urban and Katz (1983) published another article documenting the economic benefits of the model. So who takes the first step? Many firms already have, such as ZS and MDS, which are run by academics who continue to publish and cycle leading-edge practical findings back into the academic community. Perhaps such firms should be encouraged to partner with business schools; perhaps business schools should work to partner with existing intermediaries while also encouraging and nurturing new ones.

Of the great amount of data that intermediaries collect, some are of little commercial value after they go out of date; yet they often retain significant academic value. Proactively publicizing the availability of such data for academic purposes might motivate high-quality research. The availability of the PIMS database to academics, offered by the Strategic Planning 
Institute (http://www.pimsonline.com/about_pims_db.htm) spawned considerable research (e.g., Boulding and Staelin 1990), and IRI has done something similar with its data set initiative through ISMS (http://mktsci.journal.informs.org/cgi/content/abstract/27/4/745).

Thus for intermediaries, we recommend the following: (1) recognize the possibility of breakthrough work that could lead to new lines of business, achieved by working with academics; (2) leverage the publicity and credibility of copublishing with academics; (3) seek appropriate academic partners at both academic conferences (i.e., many academics, few appropriate partners) and industry conferences (attending academics are likely attractive partners); (4) offer internships to faculty and Ph.D. students; and (5) seek creative business relationships with business schools (e.g., research/consulting blends, B-School office of the firm?), such that they embrace the medical school model for mutual gain.

\section{Implications for practitioners}

Finally, we recognize practitioners as the ultimate consumers of marketing models: If they do not realize the potential benefit of academic developments (directly or through intermediaries), then why should academics bother? In the lean modern world, managers are overburdened and underresourced; yet they cannot use what they do not know. If an academicintermediary partnership succeeds, it creates higher visibility of the availability and benefits of marketing models, a necessary precondition for adoption and use.

Nor will practitioners use what they do not understand. Managers have an ongoing need for education, which should encompass both "just-in-case" education (e.g., as in MBA and executive MBA programs, which give managers concepts and tools just in case they need them) and "just-in-time" education, such that knowledge of which models are available and possible is communicated to the manager as soon as a business problem arises. Such just-in-time education 
can rely on more traditional action learning settings, including multiple business teams that face a business problem, or online, using web-based, interactive meeting technology. Our interconnected, web-based society makes the delivery of just-in-time education simpler than ever before, as well as an educational mode academics should embrace.

In addition, managers, academics, and intermediaries should work together to document the value of education and training. It is in all of our interests to study what works, what does not, and why; education and training, whether just-in-time or just-in-case, thus becomes an investment, with a measurable ROI, not an expense. The ISMS-MSI Practice Prize finalist papers and associated video reports offer excellent documentation of such potential benefits.

Dan Elwing, President of ABB Electric, during his Edelman Prize competition presentation (Gensch, Aversa, and Moore 1990), described the changes he and his firm made to use marketing decision modeling. Among his memorable comments (see the video at http://techtv.mit.edu/collections/edelmanprize) was the following: "Management had to lead by example. I had to do regression. How hard would you work if your manager did not know your job?" Elwing thus calls effectively for adding more analytics into business programs at all levels - marketing metrics, marketing models/engineering, and the use of MDSS for better decisions. As a corollary, we note that we need to provide students with an adequate skill base so that they can undertake such analyses, or at least understand their potential and limitations.

As recommendations for practitioners, we thus propose: (1) engage academics in just-intime education to learn marketing concepts and models in the context of their own problem; (2) document and communicate both short- and long-term (and soft and hard) benefits of such interactions; (3) take marketing analytics courses with real content; (4) document model and MDSS failures, as well as successes, to enable future success that builds on those failures; and 
(5) experiment with marketing models. Some will fail. But as Hogarth (1987, p. 199) notes, "When driving at night with your headlights on, you do not necessarily see too well. However, turning your headlights off will not improve the situation."

As George Box pointed out, “All models are wrong; some are useful (Box 1979, p. 2).” The quest for useful models, while far from easy, can provide significant rewards to both the individuals and the organizations involved. But both need the courage to begin the journey. 


\section{References}

Ailawadi, Kusum L., Bari A. Harlam, Jacques César, and David Trounce (2007), “Quantifying and Improving Promotion Effectiveness at CVS.” Marketing Science 26 (4), 566-575.

Bell, Peter C. and Chris K. Anderson (2002) "In Search of Strategic Operations Research/Management Science.” Interfaces 32 (2), 28-40.

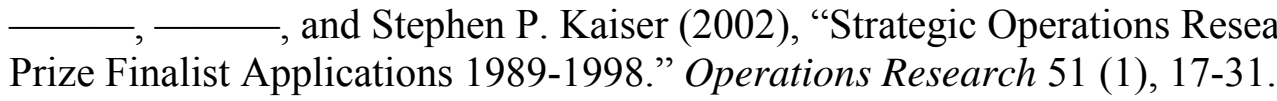

Boulding, William and Richard Staelin (1990), "Environment, Market Share and Market Power." Management Science 36 (10), 1160-1177.

Box, George E. P. (1979), "Robustness in the Strategy of Scientific Model Building," in R.L. Launer and G.N. Wilkinson, eds. Robustness in Statistics: Proceedings of a Workshop. New York: Academic Press.

Bucklin, Randolph E. and Sunil Gupta (1999), "Commercial Use of UPC Scanner Data: Industry and Academic Perspectives.” Marketing Science 18 (3), 247-273.

Danaher, Peter, John H. Roberts, Alan Simpson, and Ken Roberts (2011), “Jetstar: A Dynamic Model of Consumer Choice to Guide Brand Development." Marketing Science (Published online in Articles in Advance on February 9, 2011), 1-9.

Divakar, Suresh, Brian T. Ratchford, and Venkatesh Shankar (2005), "Practice Prize Article: CHAN4CAST: A Multichannel, Multiregion Sales Forecasting Model and Decision Support System for Consumer Packaged Goods." Marketing Science 24 (3), 334-350.

Du, Jie, Lili Xie, and Stephan Schroeder (2009), "PIN Optimal Auction Vehicle Distribution (ODAV) System: Applying Price Forecasting, Elasticity Estimation, and Genetic Algorithm to Used Vehicle Distribution." Marketing Science 28 (4), 637-644.

Elsner, Ralf, Manfred Krafft, and Arnd Huchzermeier (2004), “Optimizing Rhenania's Direct Marketing Business Through Dynamic Multilevel Modeling (DMLM) in a Multicatalog-Brand Environment." Marketing Science 23 (2), 192-206.

Fischer, Mark, Sönke Albers, Nils Wagner, and Monica Frie (2010), “Dynamic Marketing Budget Allocation Across Countries, Products, and Marketing Activities at Bayer." paper presented at 2009-2010 ISMS-MSI Practice Prize Award Ceremony, Massachusetts Institute of Technology (January 15). 
Gensch, Dennis H., Nicola Aversa, and Steven P. Moore (1990), “A Choice-Modeling Market Information System That Enabled ABB Electric to Expand Its Market Share." Interfaces 20 (1), 6-25.

Green, Paul E. and V. Srinivasan (1990), “Conjoint Analysis in Marketing: New Developments with Implications for Research and Practice.” Journal of Marketing 54 (4), 3-19.

Guadagni Peter M. and John D. C. Little (1983), “A Logit Model of Brand Choice Calibrated on Scanner Data." Marketing Science 3 (Summer), 203-238.

- and (2008), "A Logit Model of Brand Choice Calibrated on Scanner Data: A 25th Anniversary Perspective.” Marketing Science 27 (1), 26-30.

Hogarth, Robin Miles (1987), Judgment and Choice, 2d ed., New York: John Wiley \& Sons.

Kannan, P K, Barbara Kline Pope, and Sanjay Jain (2009), "Pricing Digital Content Product Lines: A Model and Application for the National Academies Press." Marketing Science 28 (4), 620-638.

Kitts, Brendan, Martin Vrieze, and David Freed (2005), “The Right Product for the Right Person: Product Recommendation from Infrequent Events." paper presented at 2005 ISMS-MSI Practice Prize Award Ceremony, Emory University (June 17).

Kumar, V., Jia Fan, Rohit Gulati, and P. Venkat (2009), "Marketing-Mix Recommendations to Manage Value Growth at P\&G Asia-Pacific.” Marketing Science 28 (4), 645-655.

and Denish Shah (2010), "Uncovering Implicit Consumer Needs for Determining Explicit Product Positioning: Growing Prudential Annuities' Variable Annuity Sales." Marketing Science (Published online in Articles in Advance on December 10, 2010), 1-9.

—, Rajkumar Venkatesan, Tim Bohling, and Denise Beckmann (2008), "The Power of CLV: Managing Customer Lifetime Value at IBM.” Marketing Science 27 (4), 585-599.

Lilien, Gary L. (2011), "Bridging the Academic-Practitioner Divide in Marketing Decision Models." Journal of Marketing, forthcoming.

Little, John D. (1970), "Models and Managers: The Concept of a Decision Calculus." Management Science 16 (8), B466-486.

(3), 9-26.

(1979) “Decision Support Systems for Marketing Managers.” Journal of Marketing 43

(2004), "Comments on Models and Managers: The Concept of a Decision Calculus." Management Science 50 (12), 1841-1861. 
Lodish, Leonard M. (2001), "Building Marketing Models that Make Money." Interfaces 31 (3), S45-S55.

Natter, Martin, Andreas Mild, Udo Wagner, and Alfred Taudes (2008), "Planning New Tariffs at tele.ring: The Application and Impact of an Integrated Segmentation Targeting, and Positioning Tool." Marketing Science 27 (4), 600-611.

— Thomas Reutterer, Andreas Mild, and Alfred Taudes (2007), "An Assortmentwide Decision-Support System for Dynamic Pricing and Promotion Planning in DIY Retailing." Marketing Science 26 (4), 576-583.

Nijs, Vincent R., Shuba Srinivasan, and Koen Pauwels (2007), "Retail-Price Drivers and Retailer Profits." Marketing Science 26 (4), 473-479.

Reda, Susan (2002). "Despite Early Positive Results, Retailers Haven't Jumped on Analytics Bandwagon." Stores 85 (3), 34.

Roberts, John H. (2000), “The Intersection of Modeling Potential and Practice." International Journal of Research in Marketing 17 (2-3), 127-134.

- (2010), "Has Research in Marketing Lost its Way?” Australasian Marketing Journal 18 (3), 161-164.

, Ujwal Kayande, and Stefan Stremersch (2009), "From Academic Research to Marketing Practice: Exploring the Marketing Science Value Chain.” Working paper, Australian National University.

— Charles J. Nelson, and Pamela D. Morrison (2005), “A Prelaunch Diffusion Model for Evaluating Market Defense Strategies.” Marketing Science 24 (1), 150-164.

Rogers, Everett M. (2003), Diffusion of Innovations, 5th ed., New York: Free Press.

Shankar, Venkatesh, Pablo Azar, and Matthew Fuller (2008), "BRAN*EQT: A Multicategory Brand Equity Model and its Application at Allstate." Marketing Science 27 (4), 567-584.

Silk, Alvin J and Glen Urban (1978), "Pre-Test-Market Evaluation of New Packaged Goods: A Model and Measurement Methodology." Journal of Marketing Research 15 (May), 171-191.

Silva-Risso, Jorge and Irina Ionova (2008), “A Nested Logit Model of Product and TransactionType Choice for Planning Automakers' Pricing and Promotions.” Marketing Science 27 (4), 545-566.

Sinha, Ashish, J. Jeffrey Inman, Yantao Wang, and Joonwook Park (2005), “Attribute Drivers: A Factor Analytic Choice Map Approach for Understanding Choices among SKUs." Marketing Science 24 (3), 351-359. 
Sullivan, L. (2005). "Fine-Tuned Pricing." Information Week (August), www.informationweek.com.

Tellis, Gerard J., Rajesh K. Chandy, Deborah J. MacInnis, and Pattana Thaivanich (2005), "Modeling the Microeffects of Television Advertising: Which Ad Works, When, Where, for How Long, and Why?" Marketing Science 24 (3), 359-366.

— Peter N. Golder, and Joseph A. Foster (2004), "Predicting Sales Takeoff for Whirlpool's New Personal Valet.” Marketing Science 23 (2), 180-191.

Tirenni, Giuliano, Abderrahim Labbi, Cesar Berrospi, André Elisseeff, Timir Bhose, Kari Pauro and Seppo Pöyhönen (2007), "Customer Equity and Lifetime Management (CELM) Finnair Case Study.” Marketing Science 26 (4), 553-565.

Urban, Glen L. and Richard Karash (1971), "Evolutionary Model Building in the Analysis of New Products.” Journal of Marketing Research 8 (February), 62-66.

and Gerald M. Katz (1983), "Pre-Test-Market Models: Validation and Managerial Implications." Journal of Marketing Research 20 (3), 221-234.

Wierenga, Berend and Gerrit H. van Bruggen (1997), "The Integration of Marketing ProblemSolving Modes and Marketing Management Support Systems." Journal of Marketing 61 (3), 2138 .

and - (2000), Marketing Management Support Systems: Principles, Tools and Implementation, Boston: Kluwer Academic Publishers.

$\longrightarrow$, $\longrightarrow$ and Richard Staelin (1999), "The Success of Marketing Management Support Systems.” Marketing Science 18 (3), 196-207.

Wiesel, Thorsten, Koen Pauwels, and Joep Arts (2010), "Marketing's Profit Impact: Quantifying Online and Off-line Funnel Progression." Marketing Science (Published online in Articles in Advance on December 30, 2010), 1-8.

Winer, Russell S. (2000), “Comments on Leeflang and Wittink.” International Journal of Research in Marketing 17 (2-3), 141-145.

Zinkhan, George M., Erich A. Joachimsthaler, and Thomas C. Kinnear (1987), "Individual Differences and Marketing Decision Support System Usage and Satisfaction." Journal of Marketing Research 24 (2), 208-214.

Zoltners, Andris A and Prabhakant Sinha (2005), "The 2004 ISMS Practice Prize Winner: Sales Territory Design: Thirty Years of Modeling and Implementation.” Marketing Science 24 (3), 313-3 
Table 1 ISMS-MSI Practice Prize Finalist Papers/Projects

\begin{tabular}{|c|c|c|c|c|}
\hline No & $\begin{array}{l}\text { Year of } \\
\text { Publication }\end{array}$ & Finalist Paper Title (Organization) & $\begin{array}{l}\text { Managerial Application (Product } \\
\text { Category/Industry) }\end{array}$ & Approach \\
\hline 1 & 2011 & $\begin{array}{l}\text { Dynamic Marketing Budget Allocation across } \\
\text { Countries, Products, and Marketing Activities (Bayer) }\end{array}$ & Advertising (pharmaceuticals) & Math programming \\
\hline 2 & 2011 & Jetstar: Driving the Brand (Jetstar) & Service design and advertising (airlines) & Choice models \\
\hline 3 & 2011 & $\begin{array}{l}\text { Uncovering Implicit Customer Needs for Determining } \\
\text { Explicit Product Positioning: Growing Prudential } \\
\text { Annuities' Variable Annuity Sales (Prudential) }\end{array}$ & Positioning and sales (financial services) & $\begin{array}{l}\text { Regression (structural equation } \\
\text { modeling) }\end{array}$ \\
\hline 4 & 2011 & $\begin{array}{l}\text { Marketing's Profit Impact: Quantifying Online and } \\
\text { Offline Funnel Progression (Inofec) }\end{array}$ & Direct marketing (B2B capital equipment) & $\begin{array}{l}\text { Time series analysis and field } \\
\text { experiments }\end{array}$ \\
\hline 5 & 2009 & $\begin{array}{l}\text { "Pricing Digital Content Product Lines: A Model and } \\
\text { Application for the National Academies Press" (NAP) }\end{array}$ & Pricing (publishing) & Discrete choice models \\
\hline 6 & 2009 & $\begin{array}{l}\text { "PIN Optimal Auction Vehicle Distribution System: } \\
\text { Applying Price Forecasting, Elasticity Estimation, and } \\
\text { Genetic Algorithm to Used Vehicle Distribution" (JD } \\
\text { Power ODAV) }\end{array}$ & Distribution (used durables) & Mathematical programming \\
\hline 7 & 2009 & $\begin{array}{l}\text { "Marketing Mix Recommendations to Maximize Value } \\
\text { Growth" at P\&G Asia-Pacific" (P\&G Asia-Pacific) }\end{array}$ & Distribution and pricing (packaged goods) & Regression analysis \\
\hline 8 & 2008 & "The Power of CLV” (IBM-CLV) & Customer account management (B2B IT) & Discrete choice models \\
\hline 9 & 2008 & $\begin{array}{l}\text { "Incentive Planning System: A DSS for Planning } \\
\text { Pricing and Promotions in the Automobile Industry" } \\
\text { (JD Power DSSIP) }\end{array}$ & Promotion (B2C durables) & Discrete choice models \\
\hline 10 & 2008 & $\begin{array}{l}\text { "BRAN*EQT: A Model and Simulator for Estimating, } \\
\text { Tracking, and Managing Multi-category Brand Equity" } \\
\text { (Allstate) }\end{array}$ & Advertising spending (financial services) & $\begin{array}{l}\text { Discrete choice models } \\
\text { Regression analysis }\end{array}$ \\
\hline 11 & 2008 & $\begin{array}{l}\text { "Planning New Tariffs at tele.ring - An Integrated STP } \\
\text { Tool Designed for Managerial Applicability" (tele.ring) }\end{array}$ & $\begin{array}{l}\text { Positioning and segmentation } \\
\text { (telecommunications) }\end{array}$ & Multidimensional scaling (MDS) \\
\hline 12 & 2007 & $\begin{array}{l}\text { "Quantifying and Improving Promotion Profitability at } \\
\text { CVS" (CVS) }\end{array}$ & Promotions (retailing) & Regression analysis \\
\hline
\end{tabular}




\begin{tabular}{|c|c|c|c|c|}
\hline 13 & 2007 & $\begin{array}{l}\text { "An Assortment wide Decision-Support System for } \\
\text { Dynamic Pricing and Promotion Planning" (bauMax) }\end{array}$ & Pricing and promotion (packaged goods) & Regression analysis \\
\hline 14 & 2007 & $\begin{array}{l}\text { "The Right Product for the Right Person: Product } \\
\text { Recommendation from Infrequent Events" } \\
\text { (Clickthrough) }\end{array}$ & Account management & Stochastic models \\
\hline 15 & 2007 & $\begin{array}{l}\text { "Customer Equity and Lifetime Management (CELM)" } \\
\text { (Finnair/IBM) }\end{array}$ & Customer account management (airlines) & Mathematical programming \\
\hline 16 & 2005 & $\begin{array}{l}\text { "Sales Territory Design: } 30 \text { Years of Modeling and } \\
\text { Implementation" (ZS) }\end{array}$ & Sales force management (various) & Mathematical programming \\
\hline 17 & 2005 & $\begin{array}{l}\text { "Attribute Drivers: A Factor Analytic Choice Map } \\
\text { Approach for Modeling Choices Among SKUs" } \\
\text { (Campbell's) }\end{array}$ & $\begin{array}{l}\text { Category and portfolio management } \\
\text { (packaged goods) }\end{array}$ & Discrete choice models \\
\hline 18 & 2005 & $\begin{array}{l}\text { "CHAN4CAST: A Multi-Channel Multi-Region } \\
\text { Forecasting Model and Decision Support System for } \\
\text { Consumer Package Goods" (PepsiCo) }\end{array}$ & $\begin{array}{l}\text { Price and promotion forecasting (packaged } \\
\text { goods) }\end{array}$ & Regression analysis \\
\hline 19 & 2005 & $\begin{array}{l}\text { "Modeling the Effects of Direct Television } \\
\text { Advertising" (Futuredontics) }\end{array}$ & $\begin{array}{l}\text { Advertising evaluation (professional } \\
\text { services) }\end{array}$ & Regression analysis \\
\hline 20 & 2004 & $\begin{array}{l}\text { "Will It Ever Fly? Modeling the Takeoff of Really New } \\
\text { Consumer Goods" (Whirlpool) }\end{array}$ & $\begin{array}{l}\text { New product management (consumer } \\
\text { durables) }\end{array}$ & Diffusion models \\
\hline 21 & 2004 & $\begin{array}{l}\text { "Defending Marketing Share Against a New Entrant" } \\
\text { (Telstra) }\end{array}$ & $\begin{array}{l}\text { Market share retention/defensive strategy } \\
\text { (telecommunications) }\end{array}$ & $\begin{array}{l}\text { Discrete choice models } \\
\text { Diffusion models }\end{array}$ \\
\hline 22 & 2004 & $\begin{array}{l}\text { "Optimizing Rhenania's Direct Marketing Business } \\
\text { Through Dynamic Multi-Level Modeling (DMLM) in a } \\
\text { Multi-Catalog-Brand Environment" (Rhenania) }\end{array}$ & Direct marketing (Direct retailing) & Mathematical programming \\
\hline
\end{tabular}


Table 2

Factor Analysis of Project Characteristics

Rotated Factor Matrix ${ }^{a}$

\begin{tabular}{|c|c|c|c|}
\hline & \multicolumn{3}{|c|}{ Factor } \\
\hline & $\begin{array}{c}1 \\
\text { Strategic Decisions }\end{array}$ & \begin{tabular}{|c|}
2 \\
Culture for Analysis
\end{tabular} & \begin{tabular}{|c|}
3 \\
Modeling and IT Capability
\end{tabular} \\
\hline Improve profits & .903 & .068 & .112 \\
\hline Useful insights & .813 & .130 & .038 \\
\hline Satisfy customer & .745 & .088 & .132 \\
\hline Adopt early & .520 & .213 & .505 \\
\hline Analytic skills & .509 & .102 & .435 \\
\hline Mix optimization & .448 & .311 & .061 \\
\hline Analytic highlight & .090 & .713 & .114 \\
\hline Company advocate & -.045 & -.655 & .350 \\
\hline Market-response models & .453 & .523 & .013 \\
\hline Unexploited value & -.128 & -.460 & -.054 \\
\hline Communication tools & .021 & .416 & .270 \\
\hline IT advantage & .265 & .445 & .756 \\
\hline State-of-art IT & .067 & .549 & .661 \\
\hline Quantitative support & .447 & -.144 & .542 \\
\hline CEO essential & .004 & -.049 & .328 \\
\hline
\end{tabular}




\section{Table 3}

\section{Cluster Profiles by Project Characteristics and Cluster Membership}

\begin{tabular}{|c|c|c|c|}
\hline & \multicolumn{3}{|c|}{ Cluster } \\
\hline & $\begin{array}{c}1 \\
\text { CEO } \\
\text { Independent }\end{array}$ & $\stackrel{2}{2}$ CEO Involved and High Skills & $\begin{array}{c}3 \\
\text { CEO Involved and Low skills }\end{array}$ \\
\hline Company advocate & 4.60 & 4.73 & 5.00 \\
\hline Unexploited value & 2.80 & 2.13 & 3.00 \\
\hline CEO essential & 2.00 & 4.47 & 5.00 \\
\hline Communication tools & 3.40 & 4.20 & 2.00 \\
\hline Analytical highlight & 2.60 & 3.06 & 2.00 \\
\hline Quantitative support & 3.10 & 4.26 & 3.50 \\
\hline Adopt early & 2.40 & 3.73 & 1.00 \\
\hline Analytical skills & 2.80 & 3.33 & 1.50 \\
\hline $\begin{array}{l}\text { Market-response } \\
\text { models }\end{array}$ & 3.80 & 3.57 & 1.00 \\
\hline Mix optimization & 2.60 & 2.87 & 1.00 \\
\hline Useful insights & 3.80 & 3.83 & 2.50 \\
\hline Satisfy customers & 3.60 & 4.13 & 2.50 \\
\hline Improve profits & 3.00 & 3.67 & 2.50 \\
\hline State-of-art IT & 3.00 & 4.20 & 1.50 \\
\hline IT advantage & 2.50 & 4.00 & 1.50 \\
\hline
\end{tabular}

Cluster 1: ZS, JD Power, JD Power-PIN, Bayer, bauMax, Clickthrough

Cluster 2: PepsiCo, Allstate, tele.ring, Rhenania, Campbell's, Finnair/IBM, IBM-CLV, Whirlpool, NAP, Jetstar, Telstra, P\&G Asia Pacific, Prudential

Cluster 3: Inofec, Futuredontics 
Table 4

Project Portfolio-Marketing Issue Versus Analytical Method

\begin{tabular}{|c|c|c|c|c|c|c|c|c|c|c|c|}
\hline \multirow{3}{*}{$\begin{array}{c}\text { Analytical } \\
\text { Method }\end{array}$} & \multicolumn{11}{|c|}{ Marketing Issue/Decision } \\
\hline & \multicolumn{11}{|c|}{--Tactical } \\
\hline & $\begin{array}{c}\text { Response } \\
\text { to New } \\
\text { Entry }\end{array}$ & Positioning & Forecasting & $\begin{array}{c}\text { Branding } \\
\text { Product } \\
\text { Design } \\
\text { NPD }\end{array}$ & $\begin{array}{l}\text { Category } \\
\text { Portfolio }\end{array}$ & CRM & Pricing & Advertising & Channels & $\begin{array}{c}\text { Sales } \\
\text { Force } \\
\text { Direct } \\
\text { Marketing }\end{array}$ & Promotion \\
\hline $\begin{array}{l}\text { Mapping/multi } \\
\text { dimensional } \\
\text { scaling (MDS) }\end{array}$ & & $\begin{array}{l}\text { Prudential } \\
\text { tele.ring }\end{array}$ & & & & & & & & & \\
\hline $\begin{array}{l}\text { Regression } \\
\text { model }\end{array}$ & & Prudential & PepsiCo & Allstate & & & $\begin{array}{c}\text { bauMax } \\
\text { P\&G } \\
\text { AP } \\
\text { PepsiCo }\end{array}$ & Futuredontics & P\&G AP & & $\begin{array}{c}\text { bauMax } \\
\text { CVS } \\
\text { PepsiCo }\end{array}$ \\
\hline Choice model & Telstra & & & Jetstar & Campbell's & IBM-CLV & NAP & $\begin{array}{c}\text { Jetstar } \\
\text { Allstate }\end{array}$ & & Inofec & $\begin{array}{c}\text { JD Power } \\
\text { DSSIP }\end{array}$ \\
\hline $\begin{array}{l}\text { Stochastic } \\
\text { process }\end{array}$ & & & & & & Clickthrough & & & & & \\
\hline $\begin{array}{l}\text { Diffusion } \\
\text { model }\end{array}$ & Telstra & & & Whirlpool & & & & & & & \\
\hline $\begin{array}{l}\text { Optimization } / \mathrm{m} \\
\text { ath } \\
\text { programming } \\
\text { model }\end{array}$ & & & & & & Finnair/IBM & & Bayer & $\begin{array}{c}\text { JD } \\
\text { Power- } \\
\text { ODAV }\end{array}$ & $\begin{array}{c}\text { Rhenania } \\
\text { Campbell's } \\
\text { ZS }\end{array}$ & \\
\hline
\end{tabular}


Figure 1

Summary of Characteristics of ISMS-MSI Practice Prize Finalist Projects

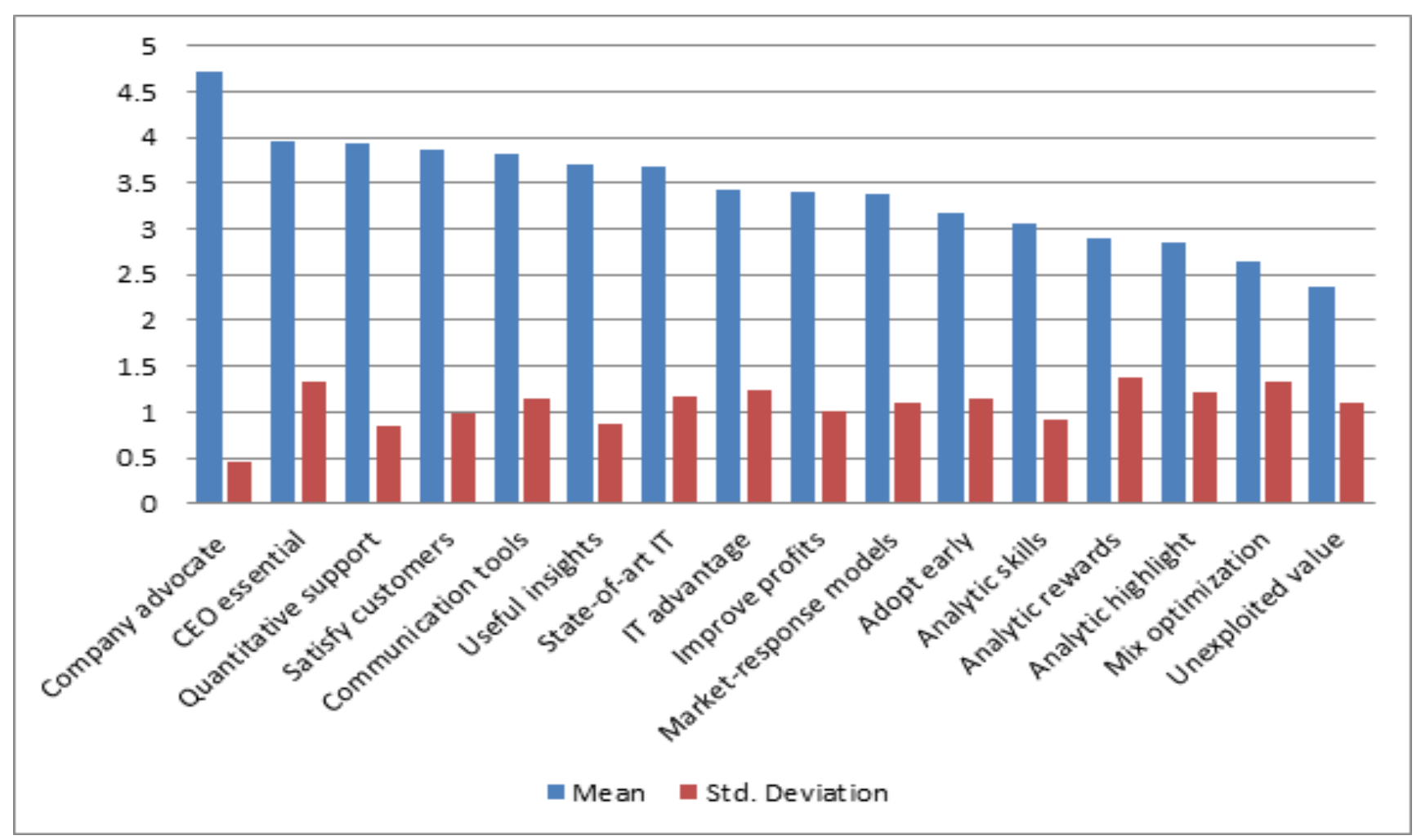


Figure 2 Positioning of Finalist Projects

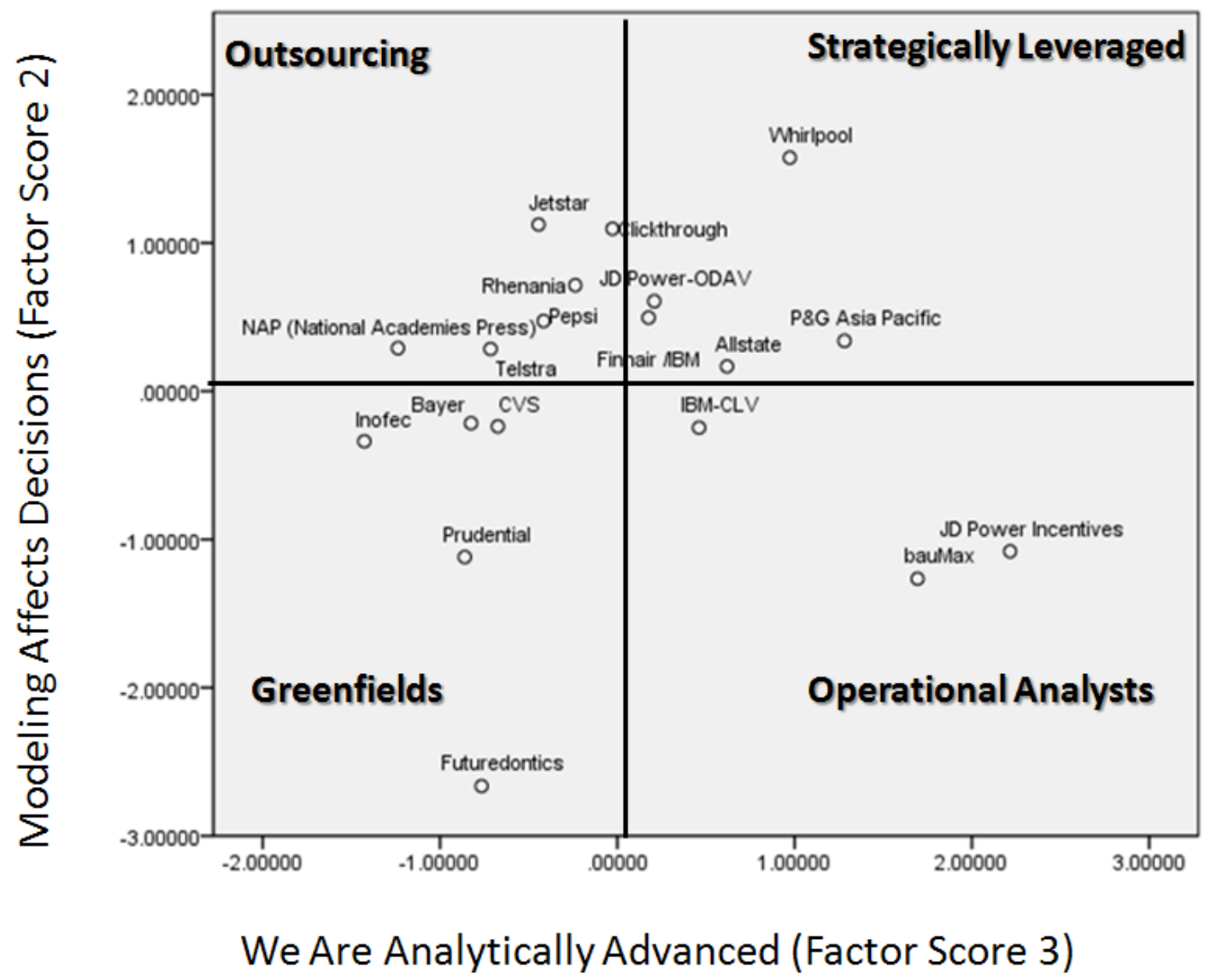

Note: Campbell's, tele.ring and ZS Associates do not appear in figure due to incomplete responses on a few items 


\section{Web Appendix 1 Interview Cover Letter and Questionnaire}

\section{Cover Letter}

Dear [Name]

First, we would like to congratulate you on having conducted marketing science research and analysis, INSERT NAME, that was judged by your peers through the ISMS-MSI Practice Prize Competition to have substantially influenced marketing practice. We are engaged in research to understand how such work comes about and what the barriers and incentives for such work are. We have constructed a questionnaire/interview guide to help us codify the collective learnings from the Practice Prize finalists and hope that you will participate. We have attached a copy of that questionnaire and we plan to use it as a guide during a phone interview with you in the near future. While you may wish to make some rough notes on this questionnaire for your own reference, there is no need to complete it at this stage. To save you time, we will talk you through it.

The goal of the interview/questionnaire is to better understand the origin of the project, some of the details of the application not included in the paper that you published in Marketing Science, and to trace what has happened to the application within the organization (and, if relevant, in other organizations). With your help we may also connect with other members of your team and/or others in the organization (or elsewhere) who might complement or supplement the information we get from you.

The report that will emerge from this work has been commissioned by the Marketing Science Institute as a part of its 50th anniversary retrospective; we also hope a version will appear in Marketing Science to highlight the work of the entries in the Practice Prize Competition and the role marketing science can play in influencing management decision making.

Your answers will remain confidential to the three researchers in the project and a research assistant. We will not use any information that could be attributable to you personally, or to the application in which you were involved, without your express written permission.

Could you please give us some time windows over the next 3-4 weeks when you would be available for a phone discussion? The call should take no more than 30-45 minutes. We will provide a dial in number for that call and will be recording your comments.

Thank you for your help.

Gary Lilien

$+18148632782$

Glilien@psu.edu
John Roberts

$+61261258112$

john.roberts@anu.edu.au
Venky Shankar

+1 979-845-3246

VShankar@mays.tamu.edu 


\section{Questionnaire}

\section{Genesis of the project: [INSERT PROJECT NAME]}

We are first interested in how the project in your Finalist entry came about.

1. How did you become acquainted with the managerial problem? (For example, did you have a pre-existing relationship, did a manager read your work or hear you present it, or was it a consulting assignment, etc.?)

\section{[If marketing intermediaries were involved as co-authors]}

2. What was the role of the marketing consulting firm in the project? That is, what were your inputs, relative to those of the consulting firm?

\section{Project drivers}

3. Why do you think that this application was an interesting problem to academia? What benefit do you feel academia gains from it?

4. What would the management of the organization have done had it not undertaken this piece of research (e.g., undertaken other research [if so, what?], continued past practice, learned from another company or market, etc.)?

5. Why do you think that this was an important problem to management and, in particular, why was the approach that you took to address it valuable?

\section{Project barriers}

Next, we would like to understand better some of the barriers that got in the way of either the execution of the study or in implementation of its findings and gaining impact from it, once it had been undertaken.

6. Time: To what extent did time constraints affect the study, if at all it did?

7. Communications: To what extent did a lack of understanding of the management environment on your part affect the study?

8. Implementation: What difficulties, if any, arose due to a lack of insight to action plan gaps by either you or the management?

9. Intra-organizational issues: What difficulties arose, if any, due to different parts of the organization having different objectives, priorities, or agendas and how did you address/overcome them?

\section{Changes in actions taken}

10. Based on the results of the application you described, what actions did the firm take that it would not have taken without your work?

\section{Nature of the project and the context-Survey questions}

11. We would like to understand your beliefs about the nature of your study and the context in which it took place on a range of different criteria. Could you please indicate the degree to which the following statements are true by checking the appropriate box? (Below, "firm" means "client firm.") 


\begin{tabular}{|c|c|c|c|c|c|}
\hline & \multicolumn{5}{|c|}{ Degree to which you agree with the statement } \\
\hline & $\begin{array}{c}\mathbf{1} \\
\text { Strongly } \\
\text { disagree }\end{array}$ & $\begin{array}{c}\mathbf{2} \\
\text { Disagree }\end{array}$ & $\begin{array}{c}\mathbf{3} \\
\text { Neither } \\
\text { Agree/ } \\
\text { Disagree }\end{array}$ & $\begin{array}{c}4 \\
\text { Agree }\end{array}$ & $\begin{array}{c}\mathbf{5} \\
\text { Strongly } \\
\text { Agree }\end{array}$ \\
\hline $\begin{array}{l}\text { 1.This project would never have gotten off the ground } \\
\text { without a strong advocate within the firm (Company } \\
\text { advocate) }\end{array}$ & & & & & \\
\hline $\begin{array}{l}\text { 2. While the project was impactful, I feel that there was a } \\
\text { lot of value in the study left unexploited (Unexploited } \\
\text { value) }\end{array}$ & & & & & \\
\hline $\begin{array}{l}\text { 3. Top management support (at the CEO level) was } \\
\text { essential to the success of this project (CEO essential) }\end{array}$ & & & & & \\
\hline $\begin{array}{l}\text { 4. The key to the realization of the benefits was having a } \\
\text { series of communications tools with which to diffuse the } \\
\text { insights throughout the organization (Communication } \\
\text { tools) }\end{array}$ & & & & & \\
\hline $\begin{array}{l}\text { 5. The firm has a recognized reward structure for those wh } \\
\text { contribute to its analytical capabilities (Analytic rewards) }\end{array}$ & & & & & \\
\hline $\begin{array}{l}\text { 6. The firm's annual reports and other publications } \\
\text { highlight the use of analytics as a core competitive } \\
\text { advantage (Analytic highlight) }\end{array}$ & & & & & \\
\hline $\begin{array}{l}\text { 7. The firm's senior management expects quantitative } \\
\text { analysis to support important marketing decisions } \\
\text { (Quantitative support) }\end{array}$ & & & & & \\
\hline $\begin{array}{l}\text { 8. The firm adopts new modeling and data analysis } \\
\text { approaches soon after they become available (Adopt early }\end{array}$ & & & & & \\
\hline $\begin{array}{l}\text { 9. The firm has mastery of many different quantitative } \\
\text { marketing analysis tools and techniques (Analytic skills) }\end{array}$ & & & & & \\
\hline $\begin{array}{l}10 \text { The firm has market response models in place for most } \\
\text { of its major products (Market-response models) }\end{array}$ & & & & & \\
\hline $\begin{array}{l}\text { 11. The firm has marketing mix optimization models in } \\
\text { place for most of its major products (Mix optimization) }\end{array}$ & & & & & \\
\hline $\begin{array}{l}\text { 12. The firm has found that the insights it obtains from } \\
\text { marketing analytics are almost always very useful (Useful } \\
\text { insights) }\end{array}$ & & & & & \\
\hline 13. The firm generally feels confident that the use of & & & & & \\
\hline
\end{tabular}




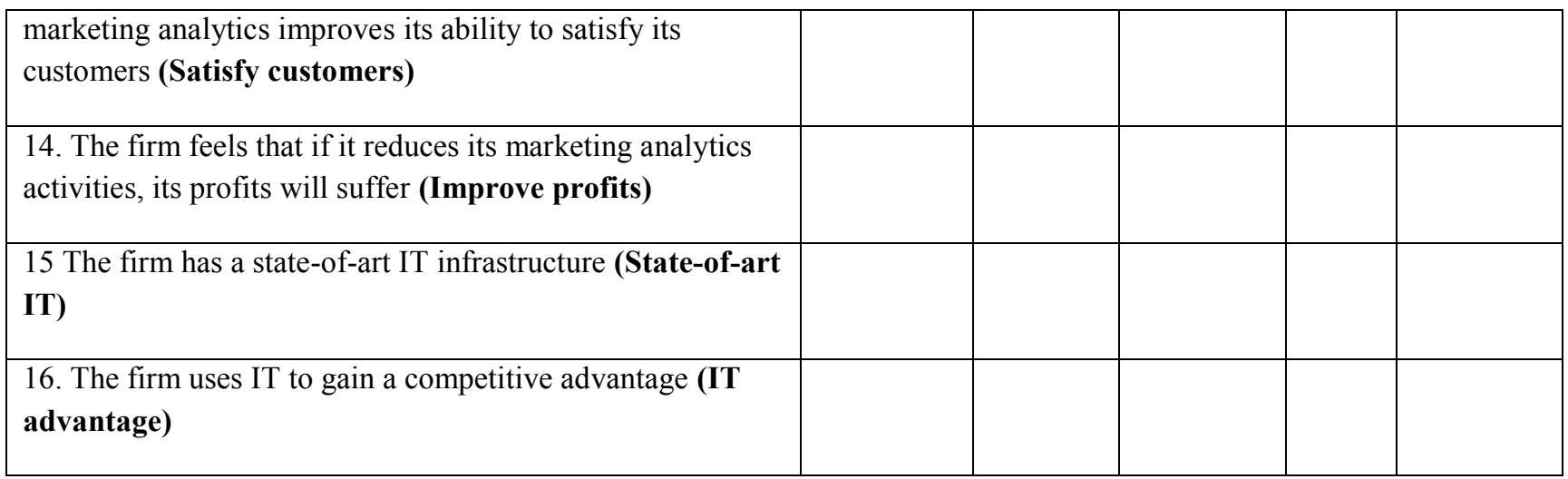

\section{Current status and realization of benefits}

12. What is the current status of the project in the organization? Can you update us with the follow-up activities in the organization and tell us about any related events?

13. Having gained the insights from the study you undertook, can you tell us the range of techniques you used to help management share those insights across the organization, and turn those insights into management actions.

\section{Postscript}

14. Have you taken this solution to other organizations and, if so, where?

15. Do you know of other work, innovations or replications that flowed from this study within the organization for which you undertook it?

\section{Contacts}

We are keen to get the perspective of as many players involved in this project as possible.

\section{[If marketing intermediary co-authors were involved]}

16. We note that [Names] were involved as co-authors. Are there any other consultants who were involved? If so, whom you think would be valuable for us to contact? Could you please give us their names and email addresses? We will only be asking them questions similar to the ones included in this survey, but if you have any reservations, please tell us.

\section{[If management co-authors were involved]}

17. We note that [Names] were involved as co-authors. Are there any other executives within the firm who were involved, whom you think would be valuable for us to contact? If so, could you please give us their names and email addresses? We will only be asking them questions similar to the ones included in this survey, but if you have any reservations, please tell us.

\section{[If management co-authors were not involved]}


18. Are there any executives within the firm who were involved, whom you think would be valuable for us to contact? If so, could you please give us their names and email addresses? We will only be asking them questions similar to the ones included in this survey, but if you have any reservations, please tell us.

19. Finally, are there any other comments that you can give us that throw light on the genesis, development, implementation, and post implementation phases of this project?

20. In retrospect, if you had to do this project again, what are some of the things you would do differently?

Thank you for your assistance. We are very grateful to you for your help.

We believe that work such as what you have submitted to the Prize increases the visibility of marketing science practice, and as such, helps lead to the diffusion of new ideas and increase the penetration of established ideas. 


\section{Web Appendix 2 \\ Interesting Quotes}

The following comments are excerpts from the interviews, organized by relevant topics.

\section{Project Barriers}

"Lots of data and lots of action, but no link between the two."

-Thorsten Wiesel, Coauthor, Inofec project

"There is a tension between disenfranchising managers and using a tool for decision making."

-Martin Natter, Coauthor, bauMax project

"I would have bought a lot of beer for my web developers and try to build better bridges. That is what I would have done differently, absolutely, because like I said earlier that was a key reason why the project did not have longer legs. If we could have, you know, organizational dynamics are a very intriguing thing. Most of us going to college as students learn about it and we think that it does not matter, but I have come around."

-Marty Vriez, Coauthor, Clickthrough project

\section{Project Enablers}

"You have to start with a metric that the finance folks are comfortable with. Unless there is something new and challenging for me, I am not interested in doing another project of the same nature."

—Venky Shankar, Coauthor, Allstate project

"The switch from a legacy system to .Net and Excel was a huge milestone because everyone on the client side knows how to use Excel."

—Jorge Silva-Risso, Coauthor, JD Power DSSIP project

"The executive who championed the effort mentioned that with just this one test they [Chrysler] made more than they paid for the project."

"In the first test at GM, I asked for a simple but effective program that could give a 30\% lift....and GM increased volume 35\%."

"From a standing start in 1996, the modeling and analytics group now has 25-30 people and is the most profitable unit at J.D Power."

—Jorge Silva-Risso, Coauthor, JD Power DSSIP project

\section{Organizational Learning from the Project}

"Academia is often busy solving problems that don't exist."

-Ashish Sinha, Coauthor, Campbell's project 
"Management needed to optimize long term profitability, not customer sat."

- Manfred Krafft, Coauthor, Rhenania project

"For applications to be successful the links from analysis to strategy and from strategy to execution have to be present."

—Martin Natter, Coauthor, tele.ring project

"When you go through this and follow the rules of the company and follow the rules of the competition it is always like, in Gary [Lilien]'s words, going through a pregnancy. Right at the end of the pregnancy, you will say I don't want another baby, but after a year again, you deliver."

—V. Kumar, Coauthor, IBM-CLV, P\&G, and Prudential projects

"Very often we as academics do very complicated models, even when the simpler models are fairly robust.... I think it is very difficult for an academic going in to change a company unless the company really is already along the road of seeing a problem and wanting to fix it."

—Kusum Ailawadi, Coauthor, CVS project

"There were some real issues amongst managers as to whether in some sense if all these numbers was the way to drive an industry rather than just rolling up your sleeves and getting on with the service delivery."

—John Roberts, Coauthor, Jetstar project

"I think it is kind of interesting to think of that second order affecting our marketing models, which is not just the ones that get into Marketing Science because they beautifully, rigorously, sort of, design and calibrate it, but also the ones where it just helps managers formulate a problem and think about it and systematize their own judgment."

—John Roberts, Coauthor, Telstra project

"The practitioner community never came to know about this because it was published in JMR and Marketing Science. I should have published it also in Direct Marketing and Journal of Advertising Research."

—Gerard Tellis, Coauthor, Futuredontics project

"If one firm was doing both, the correct solution would be to give away the machine for free or very low and make the profits on the detergents. But that was not easy because different firms produced the machine and the solution, and a profit sharing solution may not have been easy and risk free."

—Gerard Tellis, Coauthor, Whirlpool project

"It is always good to keep contact with the people that you work with which I did with this company but ....People move on and I think it is always good to keep track of what is going on because I think new things start coming up. If you keep contact with them and they are already sold and you did some good stuff with them, you can always leverage that."

-P.K. Kannan, Coauthor, National Academies Press project 
"If I had to do it over again, I would make the model simpler ... the genetic algorithm is very flexible but very complex and difficult to explain to a client. I would do a rule-based system. Obviously there is no academic interest in that."

"In the real world, optimization is always under business constraints. On the one hand, the system needs be flexible enough to balance the requirements of all stakeholders by adding in various constraints. On the other, our clients needed to change their traditional thinking from considering only their own organization to the whole enterprise to fully appreciate the benefit of the system"

"It is not only hard, but hard to sell."

"We were academics; when we first demonstrated our system to clients, we were not talking their talk. I remember one client who told me, 'I hear all that music but I don't hear the song'. Learning the industry jargon and tailoring our presentation for the audience was almost as important as the model development at the beginning of the project."

—Jie Du, Coauthor, JD Power-PIN project

"We needed to find out 'do these guys believe in the effects we estimated?"

"The process resulted not only in strategic discussions but in a reorganization, a new department."

"...some products they thought did not need any more resources turned out actually to need more resources ... the process shed light on differences in goals and beliefs internally."

"If I had it to do over again, I would have a partner on site $100 \%$ of the time helping implement at the organization."

"With this project we came close to the Holy Grail of academic research, marrying rigor and relevance."

—Marc Fisher, Coauthor, Bayer project.

"You have to have a couple of home runs, then high continuity to get model implementation." "After you do all that [good technical] stuff, people could hate your solution and you have to have man/machine interaction where you allow change."

"Most academic work is not valuable to companies. If I were a company and you came to me with some of the models I have seen in academia I would laugh."

"It is not all that astounding to me that I do not have anybody who competes with ZS who is an academic."

"You have to have the 10,000 hours that Malcolm Gladwell talked about. The question is where do you put the 10,000 hours? If you are going to put the 10,000 hours on becoming an agency guru, then that is where you have to be. If you put the 10,000 hours hanging out with companies trying to figure out if you can build models for them, that is where you have to be." "I would like to write a couple of papers on all the wisdom we [ZS] have built up over time.... The reaction I get from [academic journal editors] is 'well, send me a copy and we will figure out if it fits our mandate'."

"The people who are doing both academically rigorous and impactful projects must have a personality that somehow enables them to get access to companies or else they bring some kind of a value that companies just totally appreciate." 


\section{Zoltners' Listening Story}

"One of the guys who was in my PhD class at Carnegie was working at a pharmaceutical firm and he called me in and said, 'we have this alignment problem and why don't you come and maybe look at it.' I had ways to solve alignment problems and, this is Eli Lilly, and the guy who we were talking to, who ultimately became CEO at Bristol, Myers, Squibb said, 'well I have two sales forces and I was wondering if we should have two, maybe we should only have one, consolidate them,' and I said, 'that is a great problem, but once you solve it you have to do territory alignment.' Then he said 'I don't really know how to size the sales forces. Right now one is 600 and the other is 300 , is that a good thing?' I said, 'well, good problem, once you solve it you are going to have do alignment.' Then he said 'well I got some products, I don't know which products to put on each sales force.' Then, I said, 'good problem, once you solve it you have to do alignment.' Then he said 'I don't know which products I should spend the most time on.' I said 'good problem, once you solve it you have to do alignment.' That is an early academic lesson that we are in our own space and if the world conforms to our space then we will be able to deal with it. Otherwise, it is going to become somebody else's problem."

"You can't overlook the wisdom. I remember Bluefield Kentucky. We suggested that a client put a sales person in Bluefield Kentucky and I remember some guy just yelling at me, saying 'Do you have any idea what it would be like to live in Bluefield?"

"Suppose you have a model for compensation: you are going to have the finance people involved, you are going to have the HR people involved and you are going to have the sales force involved, so you are going to have all these conflicting objectives - finance wants you to pay as little as possible, HR wants to make sure you are fair, sales wants as much money as possible. Successful implementation quite often requires that all these agendas somehow get merged. In some cases you optimize, most often you satisfice. We found that if you come out of a computer with an alignment for a sales force of 100 people, 85 of them are going to want to kill you."

—Andy Zoltners, Coauthor, ZS project

"The tenure process should give some weight to research-based consulting. We need to change the academic measurement and reward system."

—Suresh Divakar, Coauthor, PepsiCo project 


\section{Web Appendix 3 \\ Abstracts of Practice Prize Articles/Presentations}

\section{Danaher, Peter, John Roberts, Alan Simpson, and Ken Roberts (2011), "Jetstar: A Dynamic Model of Consumer Choice to Guide Brand Development." Marketing Science (Published online in Articles in Advance on February 9, 2011), 1-9.}

The paper describes a marketing science model used by Jetstar to compete in the low cost carrier marketplace. We trace the evolution of the Jetstar strategy, from its initial position, through to its efforts to grow price competitiveness and service parity, followed by a highly focused, costeffective service delivery strategy. From a methodological perspective, in addition to developing a model that incorporates dynamics, we also allow for unobserved heterogeneity of both perceptions and importance weights of process attributes. This allows us to study not only how service design and pricing initiatives shift the perceived performance of Jetstar relative to its competitors, but also how the airline is able to shift market preferences in a way that emphasizes the areas in which it has competitive advantage. During the study Jetstar market share went from $14.0 \%$ to $18.1 \%$. Significant price perception and service level disadvantages were ameliorated. Profit for Jetstar went from $\$ A 87 \mathrm{~mm}$ in $2006 / 07$, before the study was commissioned, to \$A $115 \mathrm{~mm}$ in $2007 / 08$ and $\$ A 137 \mathrm{~mm}$ in $2008 / 09$ during a period of major industry losses. We describe some of the operational challenges Jetstar overcame to realize these results and the nonquantitative benefits. Finally, we briefly outline applications of the approach in other situations.

\section{Kumar, V. and Denish Shah (2010), "Uncovering Implicit Consumer Needs for Determining Explicit Product Positioning: Growing Prudential Annuities' Variable Annuity Sales." Marketing Science (Published online in Articles in Advance on December 10, 2010), 1-9.}

A variable annuity is a popular product for investing retirement income. However, thousands of similar-looking variable annuity products are being offered by hundreds of financial service companies. In such a scenario, how can Prudential achieve meaningful product differentiation to increase the sales of its variable annuities? The solution led to the development and implementation of the "Emotion Quotient" (EQ) Tool. The EQ Tool enabled Prudential to redefine its marketing and sales approach along a proactive (as opposed to responsive) market orientation paradigm. This was accomplished by first using the EQ Tool to uncover and quantify the prevalence of certain emotions (such as fear and regret) in the prospective consumer and then pitching relevant variable annuity product(s) that could mitigate the specific behavioral risk corresponding to the prevalent emotion(s). This approach, which was backed by extensive research (as described in this study), enabled Prudential to gain over $\$ 450$ million lift in variable annuity sales and contributed to consumer welfare by promoting awareness of behavioral risk to investors who are within five years of their retirement. This research study illustrates how industry can collaborate with academia to successfully apply marketing science to solve realworld business problems. 
Fischer, Mark, Sönke Albers, Nils Wagner, and Monica Frie (2010), "Dynamic Marketing Budget Allocation Across Countries, Products, and Marketing Activities at Bayer." paper presented as 2009-2010 ISMS-MSI Practice Prize Finalist, Massachusetts Institute of Technology (January 15).

Presentation Summary from http://techtv.mit.edu/collections/isms:1132/videos.rss:

The authors report on the development of an innovative solution to the dynamic marketing allocation budget problem for multi-product, multi-country firms. Their decision support model determines near-optimal marketing budgets at the country-product-marketing-activity level in an Excel-supported environment each year. The model accounts for marketing dynamics and a product's growth potential as well as for trade-offs with respect to marketing effectiveness and profit contribution. The model has been successfully implemented at Bayer, one the world's largest firms in the pharmaceutical and chemical business, leading to an organizational transformation and a dramatic reallocation of resources, leading to a profit improvement of \$685million in a \$4billion unit at Bayer.

Wiesel, Thorsten, Koen Pauwels, and Joep Arts (2010), "Marketing's Profit Impact: Quantifying Online and Off-line Funnel Progression." Marketing Science (Published online in Articles in Advance on December 30, 2010), 1-8.

Inofec, a small- to medium-sized enterprise in the business-to-business sector, desired a more analytic approach to allocate marketing resources across communication activities and channels. We developed a conceptual framework and econometric model to empirically investigate (1) the marketing communication effects on off-line and online purchase funnel metrics and (2) the magnitude and timing of the profit impact of firm-initiated and customer-initiated contacts. We find evidence of many cross-channel effects, in particular, off-line marketing effects on online funnel metrics and online funnel metrics on off-line purchases. Moreover, marketing communication activities directly affect both early and later purchase funnel stages (website visits, online and off-line information, and quote requests). Finally, we find that online customerinitiated contacts have substantially higher profit impact than off-line firm-initiated contacts. Shifting marketing budgets toward these activities in a field experiment yielded net profit increases 14 times larger than those for the status quo allocation.

\section{Du, Jie, Lili Xie, and Stephan Schroeder (2009), "PIN Optimal Auction Vehicle Distribution (ODAV) System: Applying Price Forecasting, Elasticity Estimation, and Genetic Algorithm to Used Vehicle Distribution." Marketing Science 28 (4), 637-644.}

In addition to retailing new vehicles, automotive manufacturers in the United States sell millions of vehicles through leasing and to fleet customers every year. The majority of these vehicles are returned to the automotive manufacturers at the end of the contracted term and must be "remarketed." In 2007, about 10 million used vehicles were sold at more than 400 auctions in the United States. Large consigners face decisions every day about when, where, and at what price to offer these vehicles, which has significant financial implications for their profitability. 
To address the challenges of the distribution process, Power Information Network (PIN), a division of J.D. Power and Associates, developed the PIN Optimal Distribution of Auction Vehicles System (ODAV), an automated decision optimization system that helps remarketers maximize profits through the most advantageous distribution of their auction vehicles. At the core of the system is a combination of three models that determine the distribution of the vehicles on a daily basis: a nearest neighbor linear regression model for short-term auction price forecasting; an autoregressive integrated moving average time-series analysis model for volumeprice elasticity; and a genetic algorithm optimizer for vehicle distribution.

Since its launch in 2003, PIN has been providing ODAV services on a daily basis, and to date, more than two million vehicles have been distributed through this system. In this paper, we will describe the PIN ODAV System, its implementation, and the business impact by using as an example the experience with our largest client, Chrysler Group LLC.

\section{Kannan, P.K., Barbara Kline Pope, and Sanjay Jain (2009), "Pricing Digital Content Product Lines: A Model and Application for the National Academies Press." Marketing Science 28 (4), 620-636.}

We examine the problem of how a content provider, specifically the National Academies Press (NAP), can optimally price the different forms of its product---print and PDF---that it sells online. Whereas products in the traditional product line generally tend to be substitutes, the different content product forms could range from being substitutes to being complements across customers. Thus the content provider can possibly sell bundles of the product forms, leading to additional revenue. We first discuss NAP's decision context and describe the model we proposed for developing NAP's optimal pricing policies for its different forms. We describe the choice experiment we conducted on the publisher's website that maximally uses the online interface to collect relevant data needed to estimate our model. We show how NAP embraced the results from the model for developing a new business model and how it used the insights derived from the study to set pricing policies and monitor sales performance as a function of pricing. Finally, we perform validation of the model and the implemented policies using dynamic modeling of sales data from NAP's website. The paper illustrates how e-commerce technologies can lead to the development of optimal policies using marketing models.

\section{Kumar, V., Jia Fan, Rohit Gulati, and P. Venkat (2009), "Marketing-Mix Recommendations to Manage Value Growth at P\&G Asia-Pacific." Marketing Science 28 (4), 645-655.}

Procter \& Gamble $(\mathrm{P} \& \mathrm{G})$ Asia-Pacific is interested in managing value growth. Only after fully understanding the true effects of the marketing-mix variables can $P \& G$ managers make strategic decisions answering questions such as the following: (1) Are the P\&G brands in the detergent market inelastic or elastic with respect to price? How has the price elasticity changed over time? Can $P \& G$ increase the price of its brands to gain value growth? (2) What are the price, distribution, and sizing combinations needed to achieve the desirable value growth? (3) How can P\&G gain market share from its competitors without cannibalizing its own brands? P\&G Asia- 
Pacific approached us to develop a value growth framework to answer these questions. To generate the answers for the above questions, we develop a three-step weighted random coefficient estimator that captures the heterogeneity across cross sections (different stockkeeping units and states) and the endogeneity of distribution. Based on the parameter estimates, we provide strategic recommendations to $P \& G$ for a field test to validate our suggestions. We developed a simulator for $\mathrm{P} \& \mathrm{G}$ managers so that they can generate appropriate marketing-mix strategies for achieving the desired value growth. As a result, $\mathrm{P} \& \mathrm{G}$ gained over $\$ 39$ million in value growth over a one-year period by implementing the recommendations from our modeling approach.

\section{Silva-Risso, Jorge and Irina Ionova (2008), "A Nested Logit Model of Product and Transaction-Type Choice for Planning Automakers' Pricing and Promotions." Marketing Science 27 (4), 545-566.}

We develop a consumer response model to evaluate and plan pricing and promotions in durablegood markets. We discuss its implementation in the U.S. automotive industry, which "spends" about $\$ 45$ billion each year in price promotions. The approach is based on a random effects multinomial nested logit model of product (e.g., a vehicle model, such as Hyundai Tucson), and transaction-type choice. Transaction types include combinations of acquisition types (e.g., purchase versus lease) and pricing instruments (cash rebates, reduced APR financing, lease payment discounts). We estimate the model using hierarchical Bayes methods to capture response heterogeneity at the local market level. We find key characteristics unique to durablegood markets. First, consumers are heterogeneous in both their brand and transaction-type preferences. Second, consumers differ in their overall price sensitivity as well as in their relative sensitivity to alternative pricing instruments (e.g., cash discounts, reduced monthly payments). Third, the most effective pricing programs tend to be those in which automakers offer consumers a menu of options to choose from (e.g., a choice among a cash discount, reduced interest rate financing, or a lease payment discount). We illustrate the model through an empirical application to a sample of data drawn from J.D. Power transaction records in the entry SUV segment and discuss examples of actual implementations.

\section{Shankar, Venkatesh, Pablo Azar, and Matthew Fuller (2008), "BRAN*EQT: A Multicategory Brand Equity Model and Its Application at Allstate." Marketing Science 27 (4), 567-584.}

We develop a robust model for estimating, tracking, and managing brand equity for multicategory brands based on customer survey and financial measures. This model has two components: (1) offering value (computed from discounted cash flow analysis) and (2) relative brand importance (computed from brand choice models such as multinomial logit, heteroscedastic extreme value, and mixed logit). We apply this model to estimate the brand equity of Allstate - a leading insurance company - and its leading competitor, which compete in multiple categories. The model captures the brand's spillover effects from one category to another. In addition, we identify the dimensions that drive a brand's image, examine the relationships among advertising, brand equity, and shareholder value, and build a decision support simulator for the focal brand. Our model provides reliable estimates of brand equity, and 
our results show that advertising has a strong long-term positive influence on brand equity, which is significantly positively related to shareholder value. The model, the brand equity estimates, and the decision support simulator are used by key executives across multiple functional areas and have enabled the company to substantially gain by reallocating its advertising resources to improve brand equity and shareholder value, and by offering better guidance to analysts and investors.

\section{Natter, Martin, Andreas Mild, Udo Wagner, and Alfred Taudes (2008), "Planning New Tariffs at tele.ring: The Application and Impact of an Integrated Segmentation, Targeting, and Positioning Tool." Marketing Science 27 (4), 600-609.}

Tele.ring is a mobile phone organization selling contracts and cell phones in the Austrian market. The market situation in 2005 was highly competitive and dynamic, resulting in relatively short tariff life cycles. Excessively long lead times made tele.ring's management feel dissatisfied with their new tariff development process. Furthermore, a new competitor had entered the market, posing a major threat, and it was unclear how to effectively safeguard tele.ring's position in the market. In cooperation with the management, we implemented and tested a new segmentation, targeting, and positioning tool, which provides managers with information on their target markets, customer preferences, competitors' strengths, and customer segments. It allows for the simultaneous visualization of these data on a single map and facilitates timely and accurate decision making. In particular, we report on the design and the implementation of a new pricing scheme, "Formel 10," which became the most successful new tariff introduction in this competitive market. tele.ring's managers were very much impressed with our tool's ability to represent the market on a single map and with its capacity to allow for intuitive interpretation. In addition, the tool enhanced internal communication between its users and different stakeholders during the new tariff development process.

\section{Kumar, V., Rajkumar Venkatesan, Tim Bohling, and Denise Beckmann (2008), “The Power of CLV: Managing Customer Lifetime Value at IBM." Marketing Science 27 (4), 585-599.}

Customer management activities at firms involve making consistent decisions over time, about: (a) which customers to select for targeting, (b) determining the level of resources to be allocated to the selected customers, and (c) selecting customers to be nurtured to increase future profitability. Measurement of customer profitability and a deep understanding of the link between firm actions and customer profitability are critical for ensuring the success of the above decisions. We present the case study of how IBM used customer lifetime value (CLV) as an indicator of customer profitability and allocated marketing resources based on CLV. CLV was used as a criterion for determining the level of marketing contacts through direct mail, telesales, e-mail, and catalogs for each customer. In a pilot study implemented for about 35,000 customers, this approach led to reallocation of resources for about $14 \%$ of the customers as compared to the allocation rules used previously (which were based on past spending history). The CLV-based resource reallocation led to an increase in revenue of about $\$ 20$ million (a tenfold increase) without any changes in the level of marketing investment. Overall, the successful implementation of the CLV-based approach resulted in increased productivity from marketing 
investments. We also discuss the organizational and implementation challenges that surrounded the adoption of CLV in this firm.

\section{Tirenni, Giuliano, Abderrahim Labbi, Cesar Berrospi, André Elisseeff, Timir Bhose, Kari Pauro, and Seppo Pöyhönen, (2007), "Customer Equity and Lifetime Management (CELM) Finnair Case Study.” Marketing Science 26 (4), 553-565.}

The Customer Equity and Lifetime Management (CELM) solution is based on a decision-support system that offers marketing managers a scientific framework for the optimal planning and budgeting of targeted marketing campaigns to maximize return on marketing investments. The CELM technology combines advanced models of Markov decision processes (MDPs), Monte Carlo simulation, and portfolio optimization. MDPs are used to model customer dynamics and to find optimal marketing policies that maximize the value generated by a customer over a given time horizon. Lifetime value optimization is achieved through dynamic programming algorithms that identify which marketing actions, such as cross-selling, up-selling, and loyalty marketing campaigns, transition customers to better value and loyalty states. The CELM technology can also be used to simulate the financial impact of a given marketing policy using Monte Carlo simulation. This allows marketing managers to simulate several targeting scenarios to assess budget requirements and the expected impact of a given marketing policy. The benefits of the solution are illustrated with the Finnair case study, where CELM has been used to optimize marketing planning and budgeting for Finnair's frequent-flyer program (FFP).

Natter, Martin, Thomas Reutterer, Andreas Mild, and Alfred Taudes (2007), “An Assortmentwide Decision-Support System for Dynamic Pricing and Promotion Planning in DIY Retailing." Marketing Science 26 (4), 576-583.

The main objective of this report is to describe a decision-support system for dynamic retail pricing and promotion planning. Our weekly demand model incorporates price, reference price effects, seasonality, article availability information, features and discounts. Building on previous research, we quantify demand interdependencies and integrate the resulting profit-lifting effects into the optimal pricing model. The methodology was developed and implemented at bauMax, an Austrian Do-It-Yourself (DIY) retailer. Along with the practical requirements, an objective function was employed that can be used as a vehicle for implementing a retailer's strategy. Eight pricing rounds with thousands of different Stock Keeping Units (SKUs) have each served as a testing ground for our approach. Based on various benchmarking methods, a positive impact on profit was reported. The currently implemented marketing decision-support system increased gross profit on average by 8.1 and sales by 2.1 percent.

Kitts, Brendan, Martin Vrieze, and David Freed (2005), "The Right Product for the Right Person: Product Recommendation from Infrequent Events," paper presented as 2005 ISMS-MSI Practice Prize Finalist, Emory University (June 17).

Presentation Summary from http://techtv.mit.edu/collections/isms:1135/videos.rss: 
The authors describe five years of work developing, analyzing, and running one-to-one marketing systems in a successful cross-channel retailer. The problem is targeting the right customer with the right product. Previously our participating retail chain, Clickthrough, had sent e-mails to opt-in customers featuring products chosen by the marketing department. In 1999 they ran a pilot study in which they replaced the static products with product offers selected by a probabilistic one-to-one recommendation algorithm. The pilot test was very successful. Clickthrough increased profit by $40 \%$, revenue by $38 \%$, and units sold by $61 \%$. The full system was deployed in October 2000 that generated a response rate increase of over 100\%. From 20002005 , the recommendation system has continued to be used each week, and the retailer continues to maintain control groups and report on performance.

\section{Ailawadi, Kusum L., Bari A. Harlam, Jacques César, and David Trounce (2007), "Quantifying and Improving Promotion Effectiveness at CVS." Marketing Science 26 (4), 566-575.}

We quantified the net unit and profit impact of each promotion offered in 2003 by CVS, a leading U.S. drug retail chain, and analyzed the key drivers of variation in this net impact. We used this analysis to identify the least effective promotions and conducted a controlled field test to demonstrate the impact of eliminating them before chainwide implementation. Our key findings are as follows. First, approximately $45 \%$ of the gross lift from promotions is incremental for CVS. Further, for every unit of gross lift, 0.16 unit of some other product is purchased elsewhere in the store. Still, more than $50 \%$ of promotions are not profitable because the lower promotional margin is not sufficiently offset by incremental units. Second, there is substantial variation in net profit impact across categories. Our field test shows that eliminating promotions chainwide in 15 of the worst performing categories will decrease sales by about $\$ 7.8$ million but will improve profit by approximately $\$ 52.6$ million. This is very impressive given that CVS front store sales in 2003 were approximately $\$ 9$ billion while the net profit impact of promotions was -\$25.3 million.

\section{Zoltners, Andris A. and Prabhakant Sinha (2005), "The 2004 ISMS Practice Prize Winner Sales Territory Design: Thirty Years of Modeling and Implementation." Marketing Science 24 (3), 313-331.}

Sales territory alignment is the assignment of accounts and their associated selling activities to salespeople and teams. Models, systems, processes, and wisdom have evolved over 1,500 project implementations for 500 companies with 500,000 sales territories. Optimization models have evolved over time to explicitly consider travel time along road networks and customer disruption. Personal computers with continually increasing speeds and storage capabilities, the Internet, and mapping databases have enabled the development of systems that communicate alignments visually to sales managers. Because of their combinatorial complexity, multiple conflicting objectives, and personnel aspects that touch everyone in the sales force, the alignment models were unable to completely solve the sales territory alignment issues faced by companies. Consequently, processes that add local managerial knowledge were used to communicate and enhance model-derived solutions, while achieving very high implementation rates. The territory alignment team gains knowledge with every sales territory alignment. Alignment insights get 
codified. Alignment experts improve every model-derived solution. This wisdom becomes part of subsequent alignments and triggers further innovation. Over time, the role of processes and wisdom becomes larger than the role of the models and systems.

\section{Divakar, Suresh, Brian T. Ratchford, and Venkatesh Shankar (2005), "CHAN4CAST: A Multichannel, Multiregion Sales Forecasting Model and Decision Support System for Consumer Packaged Goods." Marketing Science 24 (3), 334-350.}

We discuss the development and implementation of CHAN4CASTa, sales forecasting model, by pack size, category, channel, region, customer account and a Web-based decision support system (DSS) for consumer packaged goods. In addition to capturing the effects of such variables as past sales, trend, own and competitor prices and promotional variables, and seasonality, the model accounts for the effects of temperatures, significant holidays, new product introductions, trading day corrections, and adjustments to the wholesale level. In general, the model forecasts sales volume satisfactorily for a leading consumer packaged goods company. The DSS enables topand mid-level executives in sales, marketing, strategic planning, and finance to develop accurate forecasts of sales volume, plan prices, and promotional activities over a long time horizon; to track sales response to marketing actions over time; and to simulate forecast scenarios based on possible marketing decisions and other variables. CHAN4CAST is being rolled out for more users and more divisions in the company. The key take-aways are that successful development and implementation of a rigorous marketing science model require a strong internal champion, a careful balance between modeling sophistication and practical relevance, good diagnostic features, regular validations, and greater attention to the development of a fast and responsive DSS.

\section{Sinha, Ashish, J. Jeffrey Inman, Yantao Wang, and Joonwook Park (2005), "Attribute Drivers: A Factor Analytic Choice Map Approach for Understanding Choices among SKUs." Marketing Science 24 (3), 351-359.}

We describe the implementation of Attribute Drivers (AD), a flagship panel product of Information Resources Incorporated, at Campbell Soup Company. AD combines the parsimony of a factor analytic choice map approach with the ability to incorporate the dynamics of choice decisions to understand consumers' choices among stock keeping units (SKUs). A key distinguishing feature of this methodology is its scalability and applicability to large-scale problems.

The application of AD helped Campbell's grow its revenues at twice the category growth rate. This revenue growth was achieved in a climate of high product proliferation, a slow economy, and a five-year decline in unit sales at a category level. Campbell has applied AD in four primary areas: making restaging decisions, identifying potential line extensions and estimating their volume and market share impacts at the brand and category level, performing price gap analysis for new products, and increasing responsiveness to consumers' needs. The model has been used by several other clients, testifying to its transportability. 
Tellis, Gerard J., Rajesh K. Chandy, Deborah J. MacInnis, and Pattana Thaivanich (2005), "Modeling the Microeffects of Television Advertising: Which Ad Works, When, Where, for How Long, and Why?" Marketing Science 24 (3), 359-366.

Most past research has focused on how aggregate advertising works in field settings. However, the information most critical to managers is which ad works, in which medium or vehicle, at what time of the day, at what level of repetition, and for how long. Managers also need to know why a particular ad works in terms of the characteristics (or cues) of its creative. The proposed model addresses these issues. It provides a comprehensive method to evaluate the effect of TV advertising on sales by simultaneously separating the effects of the ad itself from that of the time, placement (channel), creative cues, repetition, age of the ad, and age of the market. It also captures ad decay by hour to avoid problems of data aggregation. No model in the literature provides such an in-depth and comprehensive analysis of advertising effectiveness. Applications of the model have saved millions of dollars in costs of media and design of creatives.

\section{Elsner, Ralf, Manfred Krafft, and Arnd Huchzermeier (2004), "Optimizing Rhenania's Direct Marketing Business through Dynamic Multilevel Modeling (DMLM) in a Multicatalog-Brand Environment." Marketing Science 23 (2), 192-206.}

We introduce Dynamic Multilevel Modeling (DMLM) to a multicatalog-brand environment to determine the optimal frequency, size, and customer segmentation of direct marketing activities. This optimization method leverages multicatalog-brand effects including the utilization of prior customer ordering behavior, maximization of customer value and customer share, and economies of scale and scope in printing and mailing. This enhancement of the original DMLM-approach is called Dynamic Multidimensional Marketing (DMDM). With DMLM alone, Rhenania, a German direct mail order company, turned its catalog mailing practices around and consequently rose from the number 5 to the number 2 market position. The DMLM approach was so effective that two major competitors could be bought out. Improvements provided by DMDM were threefold: more efficient resource allocation across all catalog brands, more accurate customer microsegmentation, and more effective reactivation. Presently, the company's target is to transform single-brand customer relationships into two- or three-brand relationships with higher revenue per customer. As a consequence, the Rhenania group's performance was decoupled from the overall market trend.

\section{Tellis, Gerard J., Peter N. Golder, and Joseph A. Foster (2004), "Predicting Sales Takeoff for Whirlpool's New Personal Valet.” Marketing Science 23 (2), 180-191.}

The introduction of really new products creates many dilemmas for managers. Initially, they must develop a launch strategy in the face of great uncertainty about the product's potential. After launch, they need guidance about whether to pull the plug on a new product with lackluster sales (prior to takeoff) or persist with a product that could ultimately be a failure. Our results and model of the takeoff in sales of new products provide some guidance on these complex managerial decisions. Prior to our study on sales takeoff, a manager's only recourse to analyzing new product growth would have been diffusion models. However, these models have typically used new product sales beginning at or around the takeoff, have assumed takeoff, and have not 
explicitly modeled it. In contrast, our model addresses the time from commercialization until takeoff, thus providing insights during the period of greatest uncertainty. Whirlpool Corporation used our model to guide their decision making in the testing and launch of a completely new consumer durable, the Personal Valet.

\section{Roberts, John H., Charles J. Nelson, and Pamela D. Morrison (2005), "A Prelaunch Diffusion Model for Evaluating Market Defense Strategies.” Marketing Science 24 (1), 150-164.}

This paper describes the development and application of a marketing model to help set an incumbent's defensive marketing strategy prior to a new competitor's launch. The management problem addressed is to assess the market share impact of a new entrant in the residential Australian long distance telephone call market and determine the factors that would influence its dynamics and ultimate market appeal.

The paper uses probability flow models to provide a framework to generate forecasts and assess the determinants of share loss. We develop models at two levels of complexity to give both simple, robust forecasts and more detailed diagnostic analysis of the effect of marketing actions. The models are calibrated prior to the new entrant's launch, enabling preemptive marketing strategies to be put in place by the defending company. The equilibrium level of consideration of the new entrant was driven by respondents' strength of relationship with the defender and inertia, while trial was more price-based. Continued use of the defender depends on both service factors and price. The rate at which share loss eventuates is negatively related to the defender's perceived responsiveness, saving money being the only reason to switch, and risk aversion.

Prelaunch model forecasts, validated six months after launch using both aggregate monthly sales data and detailed tracking surveys, are shown to closely follow the actual evolution of the market. The paper provides a closed-form multistate model of the new entrant's diffusion, a methodology for the prelaunch calibration of dynamic models in practice, and insights into defensive strategies for existing companies facing new entrants. 